\title{
Natural carbonation of aged alkali-activated slag concretes
}

Susan A. Bernal, ${ }^{1,2,3 *}$ Rackel San Nicolas, ${ }^{1}$ John L. Provis, ${ }^{1,2}$ Ruby Mejía de Gutiérrez, ${ }^{3}$ Jannie S.J. van Deventer ${ }^{4}$

${ }^{1}$ Department of Chemical \& Biomolecular Engineering, University of Melbourne, Victoria 3010, Australia

2 (current address) Department of Materials Science and Engineering, University of Sheffield, Sir Robert Hadfield Building, Mappin St, Sheffield S1 3JD, United Kingdom

${ }^{3}$ School of Materials Engineering, Composite Materials Group, Universidad del Valle, Cali, Colombia

${ }^{4}$ Zeobond Pty Ltd, P.O. Box 210, Somerton, Victoria 3062, Australia

* To whom correspondence should be addressed. Email s.bernal@sheffield.ac.uk, phone +44114222 5490, fax +441142225943

\begin{abstract}
Alkali-activated slag concretes stored for 7 years under atmospheric conditions are assessed, and the structural characteristics of naturally carbonated regions are determined. Concretes formulated with a $400 \mathrm{~kg} / \mathrm{m}^{3}$ and water/binder $(\mathrm{w} / \mathrm{b})$ ratio between 0.42 and 0.48 , present similar natural carbonation depths, although these concretes report different permeabilities after 28 days of curing. The inclusion of increased contents of binder leads to a substantial reduction of the $\mathrm{CO}_{2}$ penetration in these concretes, so that negligible carbonation depth values $(2 \mathrm{~mm})$ are identified in concretes formulated with $500 \mathrm{~kg} / \mathrm{m}^{3}$ of binder. Calcite, vaterite, and natron are identified as the main carbonation products formed in these concretes. These observations differ from the trends which would be expected in comparable ordinary Portland cement-based concretes, which is attributable to the physical (permeability) and chemical properties of alkali-activated slag concretes promoting high long-term stability and acceptably slow carbonation progress under natural atmospheric conditions.
\end{abstract}


Keywords: alkali-activated slag; aged concretes; durability; natural carbonation

\section{Introduction}

Alkali-activated concretes are produced using a clinker-free alkali activated slag or geopolymer binder instead of traditional Portland cement. The usual precursor materials used for the production of these binders are industrial by-products which, when combined with an alkali-activator in adequate proportions, can develop desirable strength and impermeability properties at room temperature. These are some of the main reasons why the production of these materials is often associated with low energy consumption and low $\mathrm{CO}_{2}$ emissions, when compared with Portland cement production processes $[1,2]$.

It is widely accepted that alkali-activated concretes have the potential to reach high mechanical strength at early times of curing, high stability in aggressive environments, resistance to elevated temperatures, and low permeability to chlorides, among other potentially beneficial properties [3-6]. The properties of these materials are strongly dependent on the nature and concentration of the activator, the raw materials used, and the curing conditions adopted during their production. However, it remains to some extent unknown whether alkali-activated binders will stand the test of time, as there is little existing data regarding the in-service durability performance of these materials. This is a key factor to be addressed to increase the confidence required for the acceptance of these alternative materials, and thus recognition in standards for structural concrete, leading to further potential for commercial adoption $[2,7]$.

The susceptibility of alkali-activated concretes to carbonation has been questioned over the past decade. Several authors conducting studies in pastes and mortars have noted a higher susceptibility to carbonation compared with conventional Portland cements, when it is evaluated using accelerated carbonation test methods [8-11]. This is associated with the absence of portlandite, the low $\mathrm{Ca} / \mathrm{Si}$ ratio of the binding gel and the high alkali content of the pore solution in alkali-activated binders, which have been 
identified as potentially posing a greater risk of carbonation via decalcification of the calcium silicate hydrates (C-S-H) to form calcium carbonate. The carbonation process leads in the long term to a reduction of alkalinity in the cementitious system, often accompanied by reduced mechanical performance, and potentially also the corrosion of steel reinforcement if the loss of alkalinity is sufficiently severe [12-17].

However, accelerated carbonation testing results differ from observations reported for alkali-activated concretes under service conditions, where moderate to low carbonation rates have been identified [6, 18, 19]. Shi, Krivenko and Roy [6] report natural carbonation rates of up to $1 \mathrm{~mm} /$ year in alkali-activated concretes. Xu et al. [19] also identified carbonation depths of up to $8 \mathrm{~mm}$ in the external surfaces of 18 year-old sodium carbonate/hydroxide-activated slag concretes used in challenging service conditions. This therefore provides evidence of the acceptably low susceptibility to carbonation of these concretes under natural conditions. However, the number of reports in the open literature assessing aged alkali-activated concretes is currently limited, and assessment of the structure of aged concretes is necessary for the understanding of long term performance.

A recent study assessing the effect of accelerated carbonation testing conditions on the carbonation rate of alkali-activated concretes has shown a strong dependence on relative humidity and $\mathrm{CO}_{2}$ concentration, as differences in the total porosity and in the capillary pore structure are induced under different exposure conditions [20]. It has also been identified [21] that the alkali bicarbonate phases formed as a result of the carbonation of the pore solution of an alkali-activated binder during accelerated carbonation testing differ from the alkali carbonate phases that are formed under natural carbonation conditions, and that there is a difference in pore solution $\mathrm{pH}$ of as much as 2 units between natural and accelerated exposure conditions. The important role of the pore solution chemistry of these binders, which is very different from that of conventional Portland cement systems, has not generally been considered in the application of testing protocols to determine durability performance of alkali-activated materials. Therefore, the results of accelerated testing of alkali-activated materials have been identified as 
overpredicting the degradation of the material compared to the mechanisms which are likely to occur in service [21].

So, based on the need to reconcile the available natural and accelerated carbonation data to predict the 'real' in service performance of alkali-activated concretes, this study examines in detail the natural carbonation of 7 year-old silicate-activated slag concretes formulated with different binder contents, activation conditions and water/binder ratios. Carbonation depths are determined through analysis of the loss of alkalinity, and the carbonation products formed in the surface layers of the concretes are determined through X-ray diffraction. Scanning electron microscopy is also used in order to characterize the binding gels formed in the aged concretes as a function of mix design parameters, to analyze the interfacial transition zones where identifiable, and to map the areas where more intense carbonation is taking place in these concretes.

\section{Experimental program}

\subsection{Materials and sample preparation}

The raw material used to produce the alkali-activated slag binders was a Colombian granulated blast furnace slag (GBFS) from the factory Acerías Paz del Rio. The basicity coefficient $\left(\mathrm{K}_{\mathrm{b}}=\mathrm{CaO}+\mathrm{MgO} / \mathrm{SiO}_{2}+\mathrm{Al}_{2} \mathrm{O}_{3}\right)$ and the quality coefficient $\left(\mathrm{CaO}+\mathrm{MgO}+\mathrm{Al}_{2} \mathrm{O}_{3} / \mathrm{SiO}_{2}+\mathrm{TiO}_{2}\right)$ based on the chemical composition (Table 1) were 1.01 and 1.92, respectively. Its specific gravity and Blaine fineness were $2900 \mathrm{~kg} / \mathrm{m}^{3}$ and 399 $\mathrm{m}^{2} / \mathrm{kg}$, respectively. The particle size range determined by laser granulometry was $0.1-$ $74 \mathrm{~m}$, with a $\mathrm{D}_{50}$ of $15 \mathrm{~m}$.

Table 1. Chemical composition of the GBFS used, as determined by X-ray fluorescence. $\mathrm{LOI}$ is loss on ignition at $1000^{\circ} \mathrm{C}$.

Component (mass \% as oxide)

$\begin{array}{lllllllll}\mathrm{SiO}_{2} & \mathrm{Al}_{2} \mathrm{O}_{3} & \mathrm{CaO} & \mathrm{Fe}_{2} \mathrm{O}_{3} & \mathrm{MgO} & \mathrm{TiO}_{2} & \mathrm{Na}_{2} \mathrm{O} & \text { Others } & \mathrm{LOI}\end{array}$




\begin{tabular}{llllllllll}
\hline GBFS & 33.70 & 12.80 & 45.40 & 0.96 & 1.00 & 0.50 & 0.14 & 5.50 & 2.72 \\
\hline
\end{tabular}

The alkaline activation of the GBFS was carried out using two sodium silicate solutions $\left(\mathrm{Na}_{2} \mathrm{O} \cdot r \mathrm{SiO}_{2} \cdot n \mathrm{H}_{2} \mathrm{O}\right)$. A commercial sodium silicate solution was used directly in some concrete mixes, with modulus $\left(\mathrm{M}_{\mathrm{s}}=\right.$ molar $\mathrm{SiO}_{2} / \mathrm{Na}_{2} \mathrm{O}$ ratio $) 2.4$, and composed of $32.4 \% \mathrm{SiO}_{2}, 13.5 \% \mathrm{Na}_{2} \mathrm{O}$ and $54.1 \% \mathrm{H}_{2} \mathrm{O}$ by mass. The other solution used had modulus 1.3 and was produced by adding $50 \mathrm{wt} . \% \mathrm{NaOH}$ solution to the commercial silicate solution. Binders were prepared at activator concentrations of $4 \mathrm{wt} . \% \mathrm{Na}_{2} \mathrm{O}$ and 5 wt. $\% \mathrm{Na}_{2} \mathrm{O}$, expressed relative to the mass of slag.

Crushed gravel and river sand were used as coarse and fine aggregates in the manufacture of concretes. The coarse aggregate was of $19 \mathrm{~mm}$ maximum size, with a specific gravity of $2790 \mathrm{~kg} / \mathrm{m}^{3}$ and water absorption of $1.23 \%$. The specific gravity, water absorption, and fineness modulus of the sand were $2450 \mathrm{~kg} / \mathrm{m}^{3}, 3.75 \%$ and 2.57 , respectively.

\subsection{Concrete mixes}

Alkali-activated slag concretes (AASC) were produced with binder (slag) contents of 400 and $500 \mathrm{~kg}$ per cubic meter of fresh mixture. The mixes were formulated to achieve initial slump flow consistency of around $70 \mathrm{~mm}$ with variable total water/(slag + anhydrous activator) ratios (abbreviated w/b). A summary of the mix designs of the 6 concrete mixes assessed is shown in Table 2.

Table 2. Specifications of the concrete mix designs tested

\begin{tabular}{ccccccc}
\hline \multicolumn{7}{c}{ Binder specifications } \\
\hline $\begin{array}{c}\text { Concentration of activation } \\
\left(\text { wt.\% } \mathrm{Na}_{2} \mathrm{O}\right)\end{array}$ & 4 & 4 & 5 & 4 & 4 & 5 \\
$\begin{array}{c}\mathrm{Ms}\left(\text { molar ratio } \mathrm{SiO}_{2} / \mathrm{Na}_{2} \mathrm{O}\right. \\
\text { in activator) }\end{array}$ & 1.3 & 2.4 & 2.4 & 1.3 & 2.4 & 2.4
\end{tabular}


$\mathrm{w} / \mathrm{b}$ ratio

$0.42 \quad 0.42$

0.42

0.48

$0.48 \quad 0.48$

Concrete mix (all quantities are in $\mathrm{kg} / \mathrm{m}^{3}$ of fresh concrete)

\begin{tabular}{ccccccc}
\hline Slag & 400 & 500 & 500 & 400 & 500 & 500 \\
Sodium silicate solution & 62 & 148 & 185 & 62 & 148 & 185 \\
NaOH (50 wt.\% solution) & 20 & & - & 20 & - & - \\
Coarse aggregate & 855 & 796 & 780 & 855 & 796 & 780 \\
Sand & 855 & 796 & 780 & 855 & 796 & 780 \\
Added water & 122 & 130 & 110 & 146 & 160 & 140 \\
\hline
\end{tabular}

Samples were covered with wet sponges immediately after molding to minimize superficial drying of the specimens, and consequent microcracking. After $24 \mathrm{~h}$, the cylinders were stored in a high-humidity chamber $\left(25^{\circ} \mathrm{C}\right.$, relative humidity $\left.95 \%\right)$ until testing.

\subsection{Tests conducted on concretes}

Concrete samples were tested for compressive strength following the standard procedure ASTM C39/C39M-09a (Standard Test Method for Compressive Strength of Cylindrical Concrete Specimens). Total volume of permeable voids (VPV) and water absorption were calculated according to the standard procedure ASTM C642-06 (Standard Test Method for Density, Absorption, and Voids in Hardened Concrete) for samples with $=76.2 \mathrm{~mm}$ and 50mm height, after 90 and 180 days of curing. The specimens were dried at $100^{\circ} \mathrm{C}$ for $48 \mathrm{~h}$, then submerged in water for $48 \mathrm{~h}$ to determine the saturated mass after immersion, then boiled at $100^{\circ} \mathrm{C}$ for $5 \mathrm{~h}$ to obtain the saturated mass after boiling and the immersed apparent mass. Recent results indicate that oven drying of alkali-activated slag induces structural changes in the material, and consequently modifies the pore structure of the binding phases. It is expected that the preconditioning of the specimens (drying) then impacts the VPV values determined for activated slag-based materials following this standard method; however, this is a widely used method in the characterization of concretes and therefore it is used for the assessment of the materials in this study. 
To study the natural carbonation of concretes, cylindrical specimens ( $=76.2 \mathrm{~mm}$ ) were cured for 28 days at $25^{\circ} \mathrm{C}$ and relative humidity $>90 \%$, and then stored in an open-air laboratory facility (on the roof of the Materials Engineering School, in front of the main open car-park) in Universidad del Valle, Cali, Colombia, for 7 years. The climate of the exposure site was urban, tropical, and consistent year-round, with a daytime relative humidity varying between $70 \%$ and $76 \%$ all year, and a temperature range (day and night) between $19^{\circ} \mathrm{C}$ and $38^{\circ} \mathrm{C}$. The $\mathrm{CO}_{2}$ concentration was monitored over the first 8 months of exposure, identifying variations in the range between $310 \mathrm{ppm}$ to $410 \mathrm{ppm}$.

The depth of carbonation was measured by treating the surface of a freshly cleaved specimen with a $1 \%$ solution of phenolphthalein in alcohol. In the uncarbonated part of the specimen, where the concrete was still highly alkaline, purple-red coloration was obtained, while no coloration is observed in the carbonated region. Two specimens were cleaved and tested per concrete mix, with a total of 8 measurements per specimen.

Carbonated pastes taken from the surface of the concrete specimens were analyzed by $\mathrm{X}$-ray diffraction (XRD) using a Bruker D8 Advance instrument with $\mathrm{Cu} \mathrm{K} \alpha$ radiation and a nickel filter. The tests were conducted with a step size of $0.020^{\circ}$, over a $2 \theta$ range of $3^{\circ}$ to $70^{\circ}$, and 4 seconds count time per step. The paste was extracted from concrete slices for analysis: a cant saw file was used to remove mortar from the concrete, which was then sieved to remove sand particles and washed in acetone before analysis by XRD.

To identify physical features such as microcracks and morphology in carbonated and uncarbonated areas, and to analyze the interaction between the aggregates and the bulk paste in aged concretes, environmental scanning electron microscopy (ESEM) was conducted using an FEI Quanta FEG 200 instrument with a $15 \mathrm{kV}$ accelerating voltage and a working distance of $10 \mathrm{~mm}$. Polished samples were evaluated in low vacuum mode ( $0.5 \mathrm{mBar}$ water pressure), without carbon coating to be identify carbon contents throughout the samples using a backscatter detector. A Link-Isis (Oxford Instruments) quantitative X-ray energy dispersive (EDX) detector, calibrated to ensure accurate 
quantification of relevant elements including carbon using mineral standards, was used to determine chemical compositions. The secondary electron imaging mode was also used to analyze the topography of the specimens before conducting any backscattering imaging, to avoid misinterpretation of the results as a consequence of potential roughness of the sample.

\section{Results and discussion}

\subsection{Mechanical and water absorption properties of concretes at early age}

To understand the performance of the aged concretes, it is important to first define the mechanical and water absorption properties during their first months of aging, as concretes are usually designed to achieve desired mechanical performance after 28 days of curing. Figure 1 shows the compressive strength development of the alkali-activated slag concretes assessed, as a function of water/binder $(w / b)$ ratio.

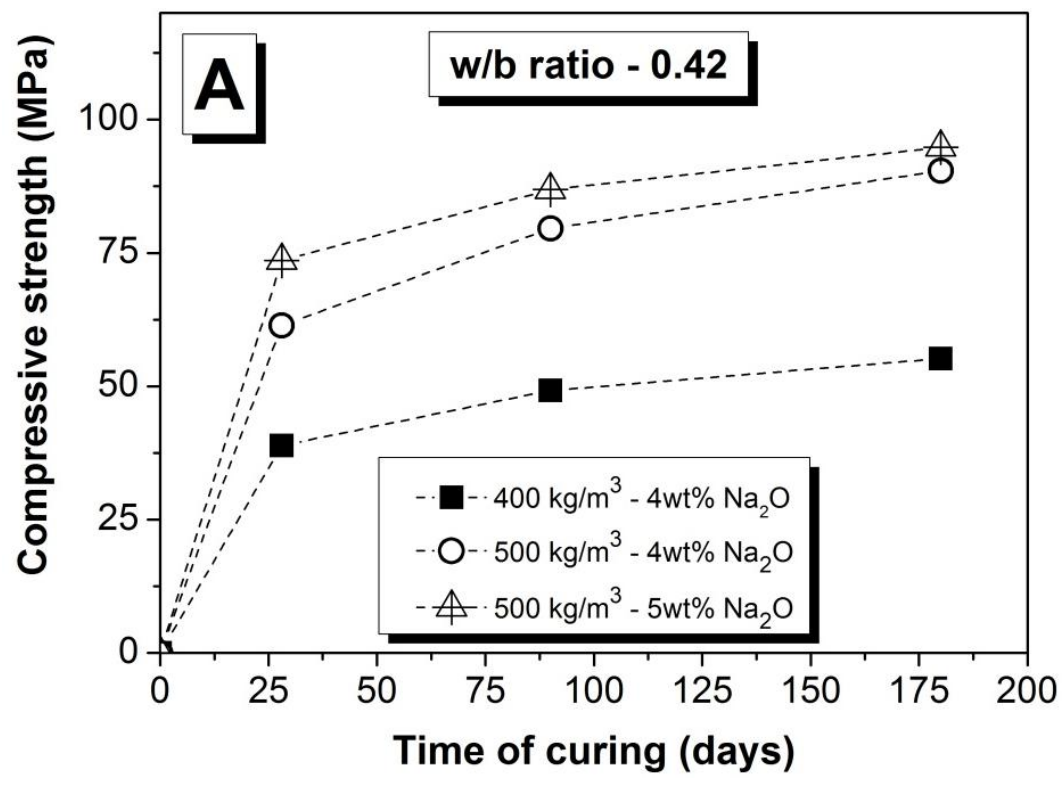




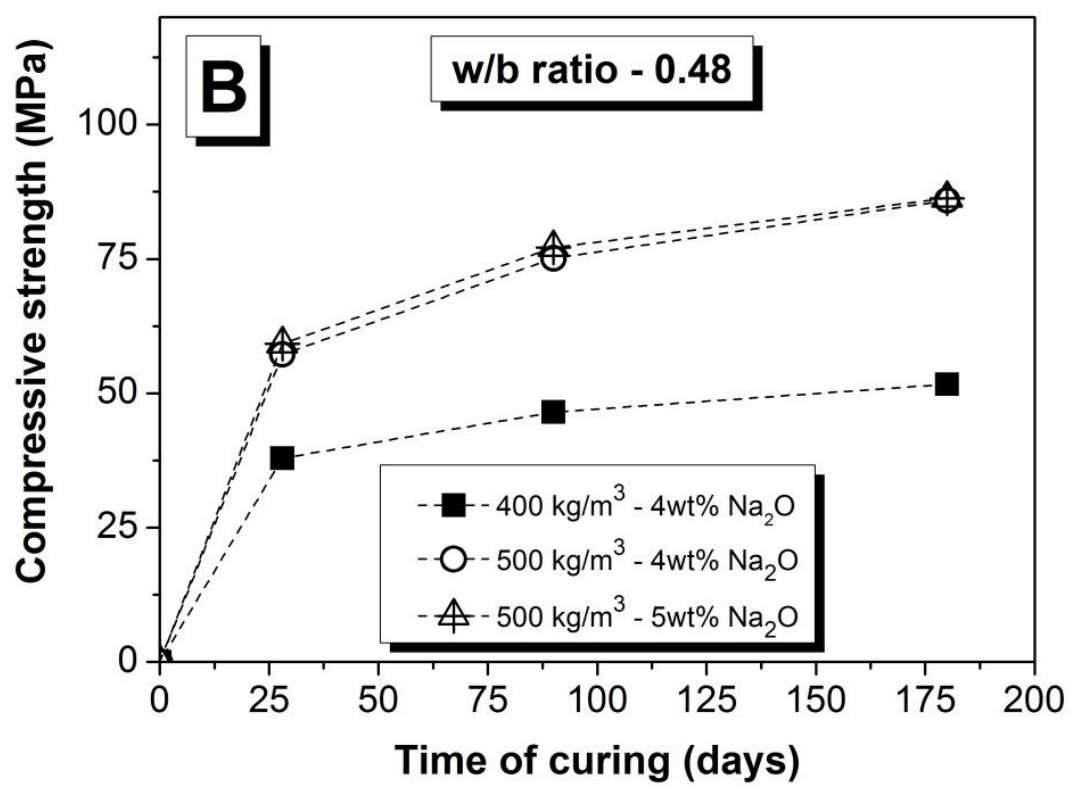

Figure 1. Compressive strength evolution of alkali-activated slag concretes as a function of mix design parameters: (A) w/b 0.42, and (B) w/b 0.48. Concretes with 400 $\mathrm{kg} / \mathrm{m}^{3}$ of slag used Ms $=1.3$, while those with $500 \mathrm{~kg} / \mathrm{m}^{3}$ used $\mathrm{Ms}=2.4$.

Concretes formulated with $500 \mathrm{~kg} / \mathrm{m}^{3}$ of slag and a w/b ratio of 0.42 (Figure 1A) show compressive strength values of up to $90 \mathrm{MPa}$ after 180 days of curing, twice as high as was obtained in concretes activated with 4 wt. $\% \mathrm{Na}_{2} \mathrm{O}, 400 \mathrm{~kg} / \mathrm{m}^{3}$ of slag, and a lower modulus activator. Concretes produced with an increased w/b ratio (0.48) (Figure 1B) and $400 \mathrm{~kg} / \mathrm{m}^{3}$ slag achieve comparable mechanical strengths to those obtained when a lower w/b ratio is used. Different results are observed in concretes with $500 \mathrm{~kg} / \mathrm{m}^{3} \mathrm{slag}$, where the higher $\mathrm{w} / \mathrm{b}$ ratio leads to a decreased mechanical strength, and no differences are identified between the two concentrations of activation.

In a previous study, it was identified [11] that the binder content of alkali-activated slag concrete has a strong effect on its water absorption properties. In Figure 2, the relationship between the mechanical strength and the volume of permeable voids (VPV) of alkali-activated slag concretes is shown. At 90 days of curing (Figure 2A), concretes formulated with $400 \mathrm{~kg} / \mathrm{m}^{3}$ slag and different w/b ratios show comparable VPV values, consistent with the compressive strength results (Figure 1). 

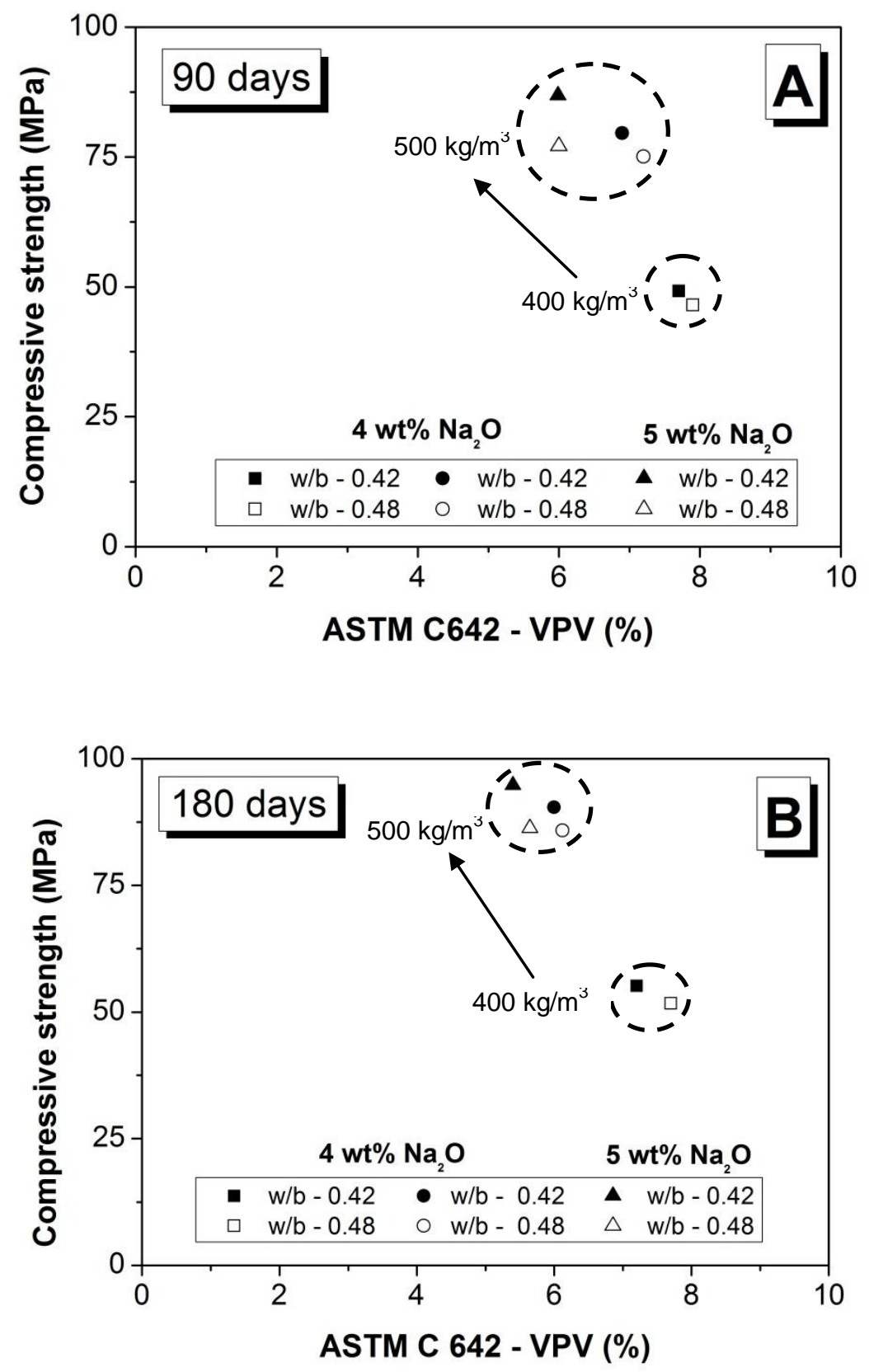

Figure 2. Relationship between compressive strength and ASTM C 642 volume of permeable voids for alkali-activated slag concretes after (A) 90 days and (B) 180 days of curing, as a function of mix design parameters

Concretes including higher contents of slag $\left(500 \mathrm{~kg} / \mathrm{m}^{3}\right)$ show comparable 90-day VPV values across all of the concretes formulated with this slag content and different $w / b$ ratios, when activated at the same concentration of activation. These results suggest that the content of binder in the concrete and the concentration of activation are the main 
factors controlling both the mechanical strength and the porosity of the material (at least as measured by this testing method).

After 180 days, slight reductions in the VPV values are observed with a decrease in the w/b ratio (Figure 2B). Less marked differences in VPV are observed in samples formulated with different concentrations of activation, when compared to the trends identified at 90 days. In contrast to the situation for Portland cement concretes [22], these results indicate that the $\mathrm{w} / \mathrm{b}$ ratio (within the range studied) does not have a strong influence on the total porosity of alkali-activated slag concretes. This is a potentially important finding, and will be examined in further detail, both below and in forthcoming publications, as it is important to determine whether this is a consequence of microstructural changes induced in the samples by drying and/or boiling as part of the ASTM C 642 test method, or whether it is a consequence of the specific microstructural development mechanism in activated slag specimens leading in the long term to the formation of binding phases with comparable microstructures, independent of the water/ binder ratio used.

\subsection{Natural carbonation}

The average natural carbonation depths of silicate-activated concretes formulated with $400 \mathrm{~kg} / \mathrm{m}^{3}$ of binder and w/b ratios of 0.42 and 0.48 , following 7 years of exposure to the atmosphere, are shown in Figure 3. In a previous study [11] it was proposed that the first stage of carbonation in alkali-activated slag concretes is mainly chemical reaction controlled, and its extent will be strongly influenced by the characteristics of the binding gel. In these concretes, with the same binder content and composition but different $w / b$ ratios, the similarity in carbonation rates may be related to the similar overall measured porosity. This indicates that because the compositions and pore volumes of the binding gels in the pastes are similar, the natural carbonation extent is not strongly affected by the w/b ratio used in concrete production. 


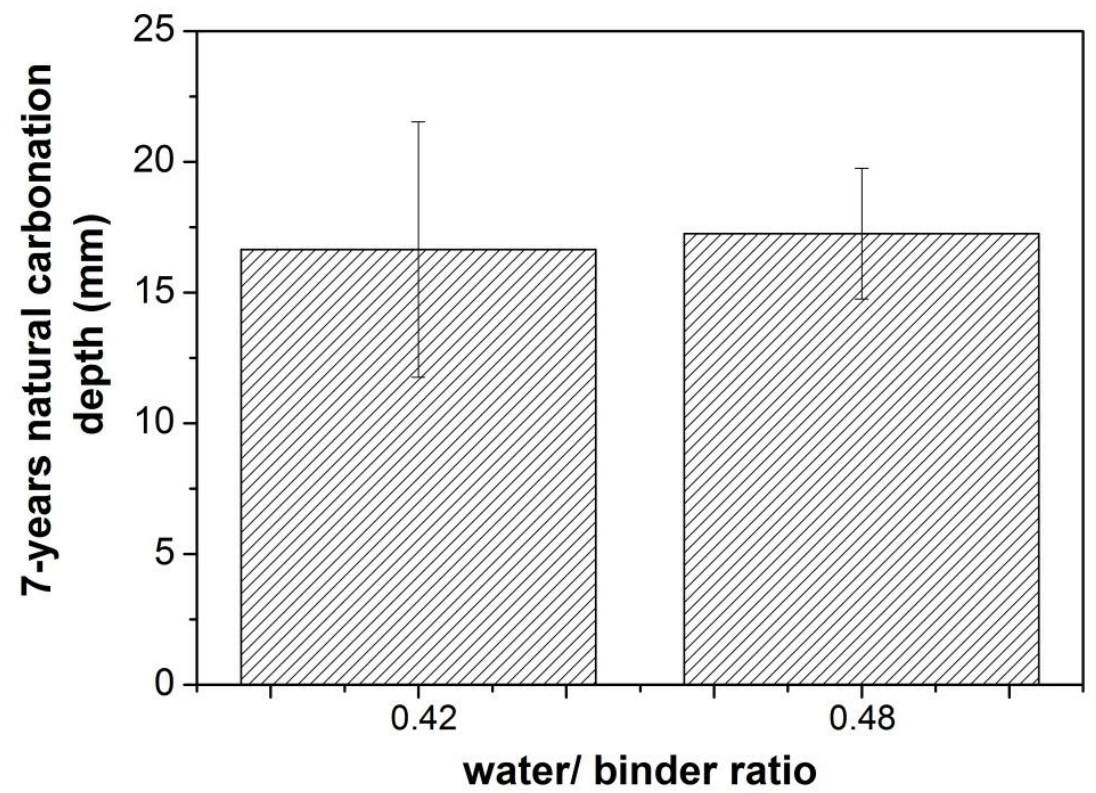

Figure 3. Natural carbonation depths (over a 7-year period) of silicate-activated slag concretes containing $400 \mathrm{~kg} / \mathrm{m}^{3}$ of slag and activated with $\mathrm{Ms}=1.3$, as a function of the water/binder ratio

In alkali-activated slag concretes formulated with increased contents of binder (500 $\mathrm{kg} / \mathrm{m}^{3}$ ), both $\mathrm{w} / \mathrm{b}$ ratio and concentration of activation seem to have a strong influence on the natural carbonation rate, as remarkable differences are observed in the carbonation rates (Figure 4). It is therefore interesting that only minor differences were identified (Figure 2) in the total porosities of these samples after 180 days of curing. It has been reported [11] that concretes based on alkali silicate-activated slag (5 wt\% $\mathrm{Na}_{2} \mathrm{O}$, w/b ratio 0.42 and 28 days of curing) with $500 \mathrm{~kg} / \mathrm{m}^{3}$ of binder show an increased capillary sorptivity compared with $400 \mathrm{~kg} / \mathrm{m}^{3}$ concretes, which was attributed to thermally induced microcracking of the samples associated with a higher content of binder. However, reduced carbonation rates were identified in the concretes formulated with higher binder contents when assessed through accelerated carbonation testing at $1 \% \mathrm{CO}_{2}$ [11], consistent with the trends in natural carbonation rates observed in this study. 


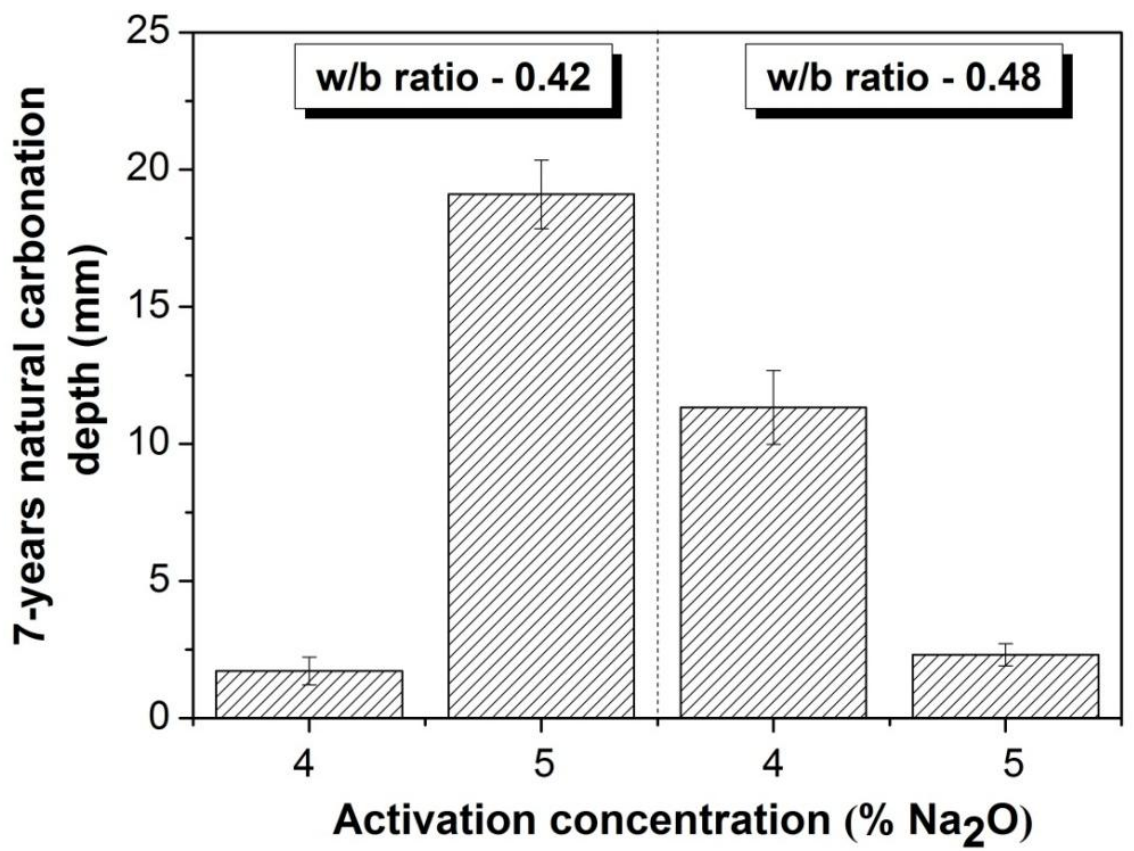

Figure 4. Natural carbonation depths of aged alkali-activated slag concretes formulated with $500 \mathrm{~kg} / \mathrm{m}^{3}$ of binder and activated at $\mathrm{Ms}=2.4$. Error bars correspond to the value of one standard deviation among 16 measurements

In naturally carbonated concretes with $500 \mathrm{~kg} / \mathrm{m}^{3}$ of binder and produced with the lower w/b ratio (0.42), a carbonation rate which is low (1.7 $\mathrm{mm}$ in 7 years) when compared with the rates reported for conventional Portland cement and blended cement concretes (e.g. 2-10 $\mathrm{mm}$ in one year reported in [23]), is identified when the concretes are produced with 4 wt. $\% \mathrm{Na}_{2} \mathrm{O}$. Conversely, concretes formulated with 5 wt. $\% \mathrm{Na}_{2} \mathrm{O}$ show a carbonation depth ten times higher than this. These results differ from the trends which would be expected based on the total porosities of these samples after 90 and 180 days of curing (Figure 2), where lower total porosity is measured in the specimens produced with higher concentrations of activation, independent of the w/b ratio. This indicates that the diffusivity of $\mathrm{CO}_{2}$ into the specimens activated with higher concentrations of activation, which is linked to the permeability of the concrete, is not the only phenomenon controlling the carbonation rate of these specimens, as it is likely that a higher concentration of alkalis in the pore solution, as identified in alkaliactivated binders formulated with higher $\mathrm{Na}_{2} \mathrm{O}$ concentrations [24], can attract an increased concentration of $\mathrm{CO}_{2}$ into the concrete to promote the formation of carbonic 
acid [25], and thus accelerate the consequent chemical interaction between this compound and the concrete.

During the alkali-activation of slag, it is expected that a higher activator dose should promote the dissolution of slags during the early stages of the reaction process, as the presence of $\mathrm{OH}^{-}$catalyzes the reaction process and increases the solubility of silica and alumina [26]. This leads to the formation of an increased content of reaction products, along with the release of more heat, which makes the material more susceptible to drying shrinkage and microcracks [27]. The combined effect of a potentially increased permeability of the specimens due to microcracking, along with the higher concentration of alkalis in the pore solution, might drive the progress of an increased extent of carbonation in specimens produced with the higher concentration of activation tested here. It is expected that the actual gels formed in alkali-activated slags at higher alkalinity conditions might present a reduced susceptibility to carbonation, as migration of alkali cations to balance the framework charges in the C-A-S-H gel, which is decalcified by carbonation in these systems, could take place [26].

The results of accelerated carbonation testing of the $400 \mathrm{~kg} / \mathrm{m}^{3}$ and $500 \mathrm{~kg} / \mathrm{m}^{3}$ concrete with $\mathrm{w} / \mathrm{b}=0.42$ have previously been presented [11], where the samples were cured for 28 days, and then exposed at a $\mathrm{CO}_{2}$ concentration of $1 \%$ (which was set as low as possible to best represent natural conditions in an accelerated test), a temperature of $25^{\circ} \mathrm{C}$ and relative humidity of $65 \%$, for up to $1000 \mathrm{~h}$ (41.7 days). This gave a carbonation depth of $13.3 \mathrm{~mm}$ for the $400 \mathrm{~kg} / \mathrm{m}^{3}$ concrete, and $10.9 \mathrm{~mm}$ for the 500 $\mathrm{kg} / \mathrm{m}^{3}$ mix, at the conclusion of the test.

Using the correlation of de Castro et al. [28], who found a square-root dependence of carbonation rate on $\mathrm{CO}_{2}$ concentration in Portland cement concretes when assuming diffusion control of carbonation, it is possible to compare the outcomes of the accelerated and natural carbonation testing for these concretes. For the $400 \mathrm{~kg} / \mathrm{m}^{3}$ concrete, the accelerated test results would predict a carbonation depth, after 7 years of exposure to natural $\mathrm{CO}_{2}$ concentrations, of $20.83 \mathrm{~mm}$, whereas the actual carbonation depth observed here (Figure 3) was $17 \mathrm{~mm}$. Thus, the accelerated test is overpredicting 
the natural carbonation rate. It is important to note that it has been reported [20] that there is not a strong effect of the relative humidity (in the range between 50\% and $80 \%$ ) on the accelerated carbonation progress within the first $250 \mathrm{~h}$ of $1 \% \mathrm{CO}_{2}$ exposure of alkali-activated slag binders. Therefore, the differences between natural and accelerated carbonation results are unlikely to be associated with the differences in relative humidity between natural (relative humidity between 70 and 76\%) and accelerated carbonation conditions (relative humidity 65\%).

For the $500 \mathrm{~kg} / \mathrm{m}^{3}$ concrete with w/b 0.42, the accelerated test (again using the data from [11]) predicts a carbonation depth of $17.1 \mathrm{~mm}$ after 7 years of carbonation, compared to the $19 \mathrm{~mm}$ observed for this concrete under natural carbonation conditions. This appears to indicate good agreement between the accelerated and natural test conditions - except for the fact that this concrete was the best-performed among the mixes tested under accelerated carbonation conditions in [11], and the worst-performed under natural conditions here. It appears that the microcracking issues in this mix, as noted above, counteract the overestimation inherent in the assumption of diffusion control in extrapolating from the accelerated test. However, this is more likely to be a fortuitous cancellation of errors rather than indicating good agreement between the accelerated and natural test conditions, taking into consideration the mechanistic explanations for the trends in carbonation rate across the sample set as presented here.

There are additional potential sources of error in this extrapolation from accelerated to natural test conditions. Firstly, it was shown in [11] that laboratory carbonation testing of alkali-activated slag concretes cannot be solely described according to a diffusivity controlled (square-root of time) mechanism, as a chemically controlled reaction better describes how accelerated carbonation proceeds in alkali-activated slag concretes. Additionally, variations in the permeability and gel structure with aging of the remnant uncarbonated core of the cylindrical samples, which would reduce diffusion coefficients and also potentially alter the gel structure at later age, are not taken into account.

In alkali-activated slag systems, it has been identified [27] that the autogenous shrinkage is dominated by the chemical shrinkage and high capillary pressure resulting 
from the self-desiccation of the binding gels, depending on the paste formulation. Higher activator concentrations lead to higher degrees of reaction of the slag, and therefore higher autogenous shrinkage as this phenomenon is mainly controlled by the chemical shrinkage of the gel. Consequently, it is likely that, in $500 \mathrm{~kg} / \mathrm{m}^{3}$ concretes activated at $5 \mathrm{wt} . \% \mathrm{Na}_{2} \mathrm{O}$, increased $\mathrm{w} / \mathrm{b}$ ratios are affecting the kinetics of reaction as discussed in section 3.1, so that a lower degree of reaction is reached at early times of curing. This reduces the effects of chemical shrinkage in the material, and thus also reduces opportunities for natural carbonation by lowering the extent of microcracking. This is consistent with the reduced mechanical strength of these concretes (Figure 2) when compared with those with similar formulation but a lower w/b ratio $(0.42)$, and the lower total porosity observed in these samples (Figure 3). This further highlights the observation that the $\mathrm{w} / \mathrm{b}$ ratio in alkali-activated concretes plays a different role compared to expectations based on observations for Portland cement concretes, and further research into the effect of the w/b ratio in the structural evolution, along other activation parameters, needs to be conducted.

\subsection{Natural carbonation products $-\mathrm{X}$-ray diffraction}

Recent studies [21, 29] have demonstrated that differences in the carbonation products formed during accelerated carbonation testing and natural carbonation of alkaliactivated slag binders, as the influence of carbonation on the pore solution is strongly dependent on the exposure conditions. Assessment of the accelerated carbonation products formed in pastes with similar formulations to some of the concretes studied here are reported in [10], and so a comparative analysis with the phases identified in pastes extracted from carbonated regions of the aged concretes becomes possible.

The main crystalline binder phases identified in the carbonated paste obtained from concretes formulated with $400 \mathrm{~kg} / \mathrm{m}^{3}$ and 4 wt.\% $\mathrm{Na}_{2} \mathrm{O}$ (Figure 5) are the calciumcontaining zeolitic phases heulandite $\left(\mathrm{CaAl}_{2} \mathrm{Si}_{7} \mathrm{O}_{18} \cdot 7 \mathrm{H}_{2} \mathrm{O}\right.$, Powder Diffraction File (PDF) \# 019-0209), and garronite $\left(\mathrm{Na}_{2} \mathrm{Ca}_{5} \mathrm{Al}_{12} \mathrm{Si}_{2} \mathrm{O}_{64} \cdot 27 \mathrm{H}_{2} \mathrm{O}\right.$, PDF\# 016-0148). In studies of alkali-activated pastes produced with the same slag used here, at up to 180 
days of age, gismondine was the key zeolitic phase identified [10, 26], and similarly at early times of curing in alkali-activated slag produced under high alkalinity conditions [30]. Garronite is the sodium-containing analogue of gismondine, and these two species can be interconverted by ion exchange processes [31]. It is interesting to note the apparent increase in incorporation of $\mathrm{Na}$ into this phase at later ages; this is in good agreement with the expected thermodynamic equilibration of a calcium-rich zeolite and a sodium-rich pore solution over an extended period of time, particularly if the calcium is being withdrawn from the binder through carbonation processes. These crystalline phases are accompanied by residual X-ray amorphous binder gel material, visible as a broad 'amorphous hump' between $25-35^{\circ} 2$

As main crystalline carbonation products (Figure 5), the calcium carbonates calcite $\left(\mathrm{CaCO}_{3}, \mathrm{PDF} \#\right.$ 047-1743) and vaterite $\left(\mathrm{CaCO}_{3}\right.$, PDF\# 060-0483) are identified, along with hydrous sodium carbonates: natron $\left(\mathrm{Na}_{2} \mathrm{CO}_{3} \cdot 10 \mathrm{H}_{2} \mathrm{O}\right.$, PDF\# 01-072-7993) and trona $\left(\mathrm{Na}_{3} \mathrm{H}\left(\mathrm{CO}_{3}\right)_{2} \cdot 2 \mathrm{H}_{2} \mathrm{O}\right.$, PDF\# 011-0643), and the sodium/calcium carbonate gaylussite $\left(\mathrm{Na}_{2} \mathrm{Ca}\left(\mathrm{CO}_{3}\right)_{2} \cdot 5 \mathrm{H}_{2} \mathrm{O}\right.$, PDF\# 002-0122). Calcite has been previously identified in the slag used in this study [26], associated with the weathering of this material, and also as the main carbonation reaction product in the fully carbonated alkali silicate activated slag pastes [10]. Vaterite was not identified in fully carbonated activated slag pastes; however, it has been observed in several studies at earlier stages of carbonation $[8,9,29]$, suggesting that this phase is consistent with the partial carbonation of the activated slag paste, as the formation of the least stable calcium carbonate polymorph (vaterite) is more likely to occur in the first stage of the carbonation reaction process [32]. It seems that the intensity of the carbonated products is higher in samples extracted from concretes formulated with w/b of 0.42 ; however, as the extraction of paste from concrete inevitably results in contamination with quartz sand particles, differences in the intensities of the peaks assigned to the carbonation products cannot be directly observed from Figure 5. 


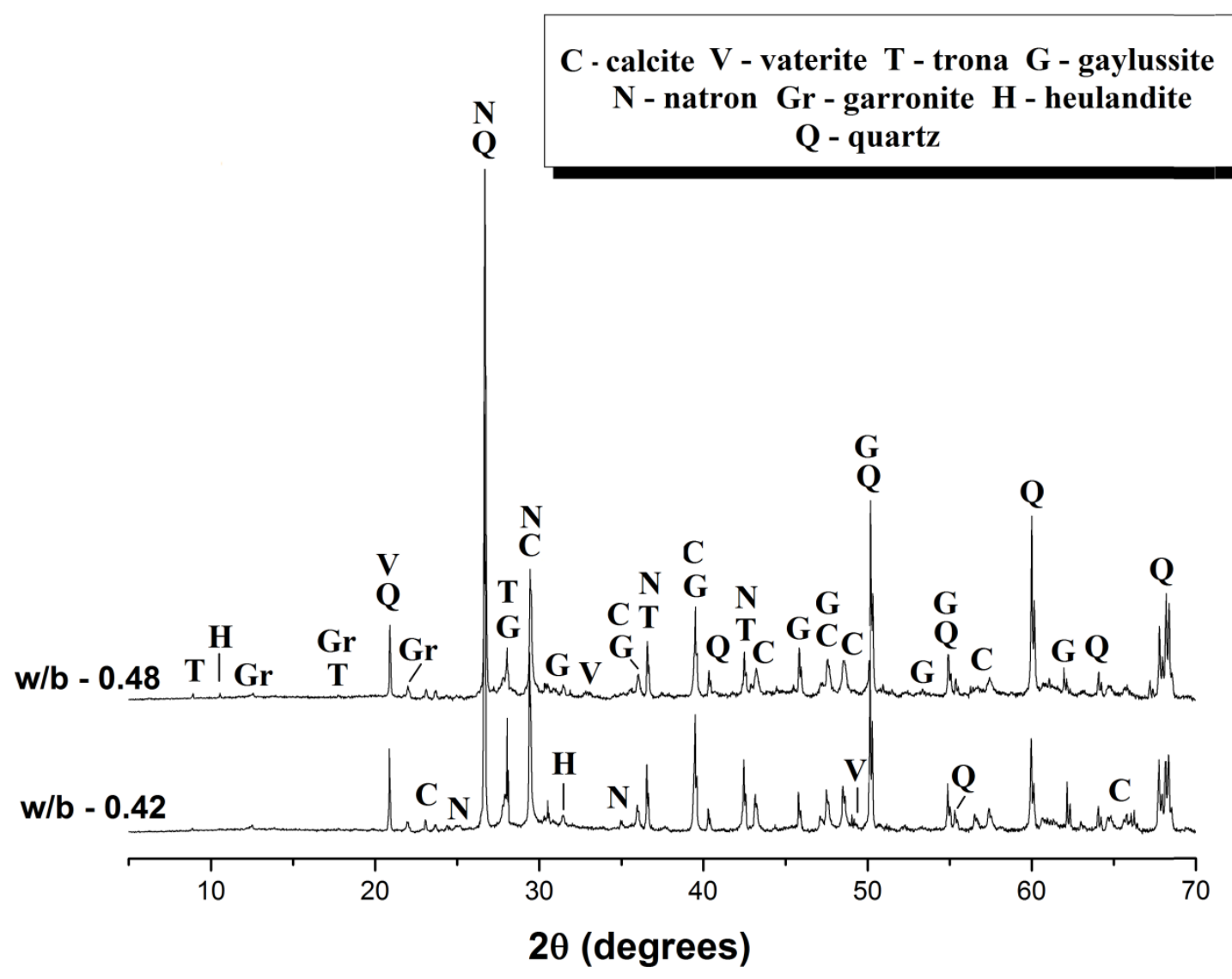

Figure 5. X-ray diffractograms of carbonated paste extracted from silicate-activated slag concretes formulated with $400 \mathrm{~kg} / \mathrm{m}^{3}$ of slag, $\mathrm{Ms}=1.3$ and $4 \mathrm{wt} . \% \mathrm{Na}_{2} \mathrm{O}$, as a function of the water/binder ratio.

A recent study [21] has shown that the formation of sodium carbonate in carbonated alkali-activated slag pastes is associated with the carbonation of the pore solution, and that the type of sodium carbonate products formed is strongly dependent on the carbonation conditions such as $\mathrm{CO}_{2}$ partial pressure, temperature and relative humidity. Considering the phase diagram as a function of temperature and gas phase $\mathrm{CO}_{2}$ concentration for the $\mathrm{Na}_{2} \mathrm{CO}_{3}-\mathrm{NaHCO}_{3}-\mathrm{CO}_{2}-\mathrm{H}_{2} \mathrm{O}$ system, as reported in [21, 33], the formation of natron and trona is consistent with the natural exposure conditions at which the samples have been naturally carbonated; both of these products can be stable in the temperature range $25-35^{\circ} \mathrm{C}$ under ambient $\mathrm{CO}_{2}$ conditions, with trona favored at the higher end of this temperature range and natron at the lower end. The formation of natron has been observed in other naturally carbonated activated slag pastes [21], and 
trona has also been observed in accelerated carbonated activated slag binders produced with the same slag used in this study [10]. The formation of these phases instead of nahcolite $\left(\mathrm{NaHCO}_{3}\right)$, which is the main sodium-containing product in accelerated carbonated activated slag binders [21], is consistent with the test conditions used here $[21,33]$.

The X-ray diffractograms of the carbonated pastes obtained from the $500 \mathrm{~kg} / \mathrm{m}^{3}$ concretes (Figure 6) are similar to those of the $400 \mathrm{~kg} / \mathrm{m}^{3}$ concretes (Figure 5). The samples with a w/b ratio of 0.48 show a much more intense trona (111) peak at $28^{\circ} 2$ than is identified in other samples, but no difference in the other trona peaks, which suggests that this is a relatively large crystallite subject to preferred orientation effects in the XRD analysis.

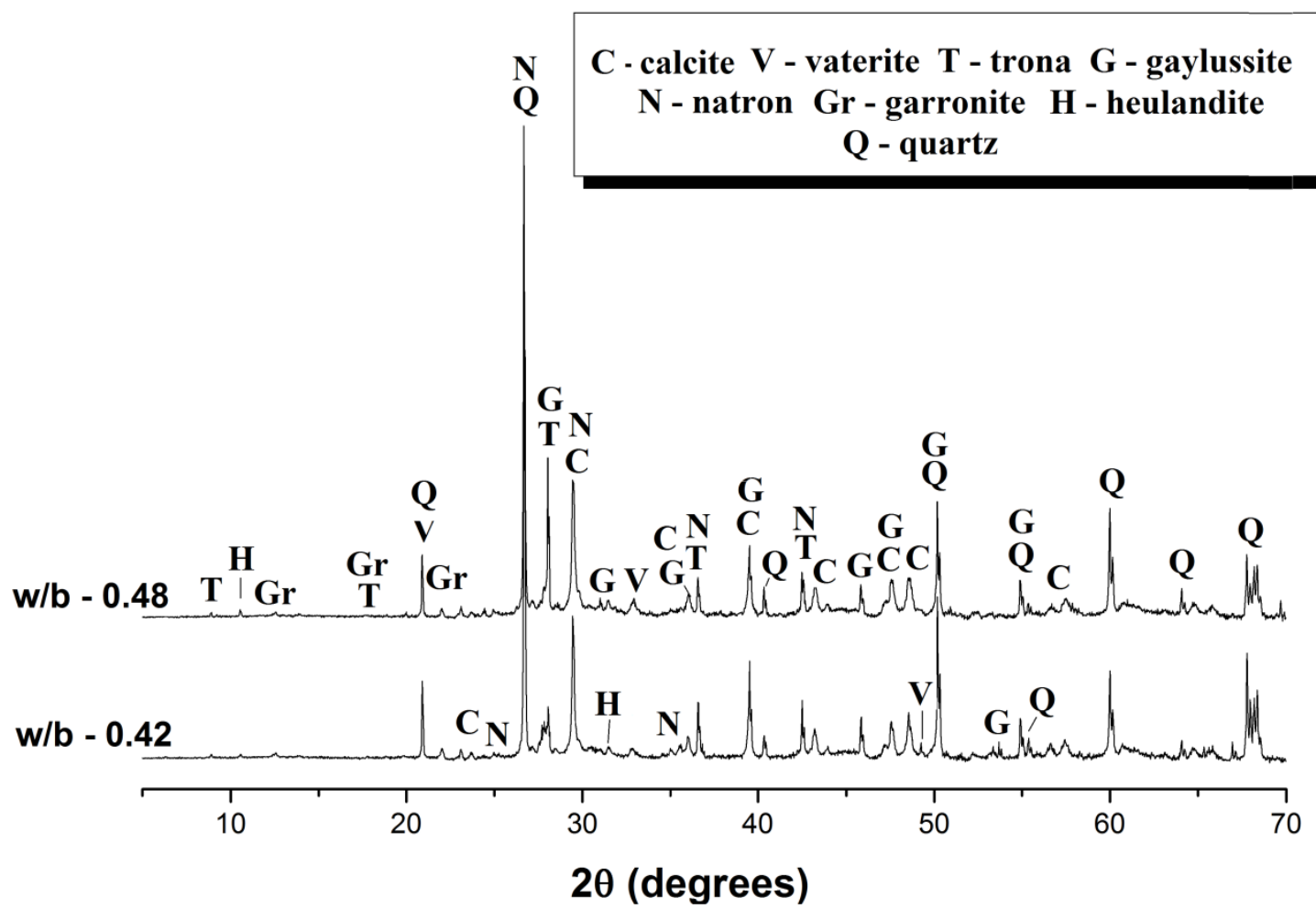

Figure6. X-ray diffractogram of carbonated paste extracted from silicate-activated slag concretes formulated with $500 \mathrm{~kg} / \mathrm{m}^{3}$ of slag, $\mathrm{Ms}=2.4$ and $4 \mathrm{wt} . \% \mathrm{Na}_{2} \mathrm{O}$, as a function of the water/binder ratio. 
In concretes with $500 \mathrm{~kg} / \mathrm{m}^{3}$ and a higher activator dose (5 wt.\% $\mathrm{Na}_{2} \mathrm{O}$ ) (Figure 7), in addition to the carbonation products identified in the discussion above, the sodiumcalcium carbonate nyerereite $\left(\mathrm{Na}_{2} \mathrm{Ca}\left(\mathrm{CO}_{3}\right)_{2}\right.$, PDF\# 028-1059) is also observed. Natural traces of nyerereite have been identified in altered natrocarbonatite mineral deposits which also include gaylussite, trona and calcite (as identified in these specimens) [34], and nyerereite is known to be the product of dehydration of gaylussite at low to moderate temperatures [35]. The formation of nyerereite in the concretes assessed here therefore suggests that these materials are likely to undergo a high degree of selfdesiccation, which is consistent with the increased carbonation rate reported for concretes including $500 \mathrm{~kg} / \mathrm{m}^{3}$ of slag activated with 5 wt. $\% \mathrm{Na}_{2} \mathrm{O}$ and a w/b ratio of 0.42 (Figure 5).

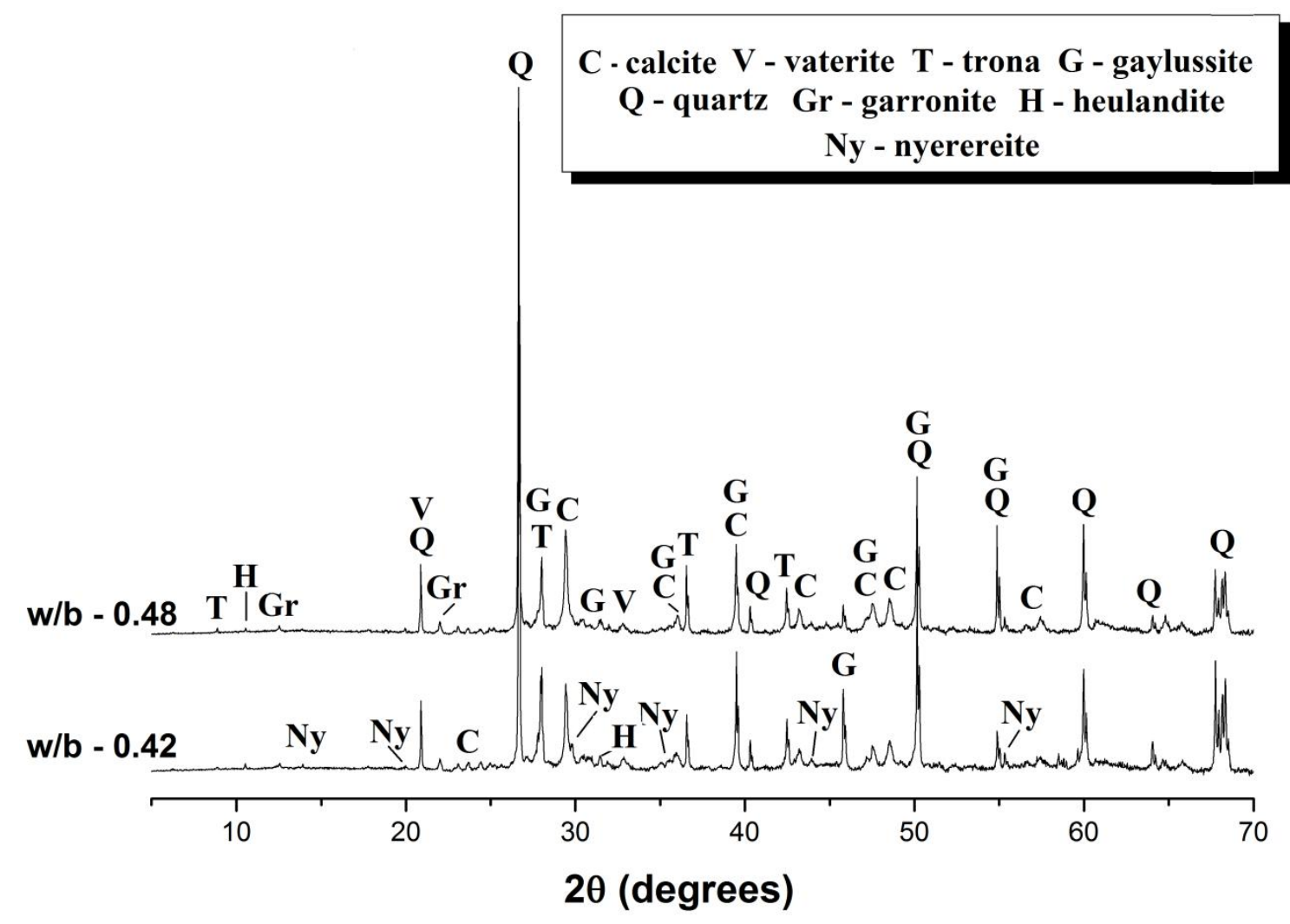

Figure 7. X-ray diffractograms of carbonated paste extracted from silicate-activated slag concretes formulated with $500 \mathrm{~kg} / \mathrm{m}^{3}$ slag and $5 \mathrm{wt} . \% \mathrm{Na}_{2} \mathrm{O}$, as a function of the water/binder ratio. 


\subsection{Scanning electron microscopy}

\subsubsection{Microstructural changes in naturally carbonated areas}

Back-scattered electron imaging (BSE) and EDX elemental mapping results for a selected area (close to the interface between carbonated and uncarbonated regions according to the phenolphthalein test) of the $400 \mathrm{~kg} / \mathrm{m}^{3}$ activated slag concrete formulated with 4 wt. $\% \mathrm{Na}_{2} \mathrm{O}$ and a w/b ratio of 0.42 are presented in Figure 8. The areas enriched in $\mathrm{Si}$ in absence of $\mathrm{Ca}$ and $\mathrm{Al}$ (marked $\mathrm{A}$ ) correspond to the siliceous aggregate, regions enriched in $\mathrm{Ca}$ (light gray in the BSE image) are unreacted slag particles, and the darker gray areas enriched in $\mathrm{Ca}, \mathrm{Si}$ and $\mathrm{Al}$ (marked $\mathrm{B}$ ) correspond to the binding gel. It has been identified [29] that the carbonation and consequent decalcification of the C-A-S-H type gel in activated slag binders will promote an increase in the concentration of $\mathrm{C}$ and $\mathrm{O}$ atoms, darkening some regions of the micrograph. This is a consequence of the lower elemental number of $\mathrm{C}$ and $\mathrm{O}$ when compared with the elements $\mathrm{Ca}, \mathrm{Al}$, and $\mathrm{Si}$ that prevail in the $\mathrm{C}-\mathrm{A}-\mathrm{S}-\mathrm{H}$ binding gel. Some evidence of this can be observed in the elemental maps in Figure 8, particularly in the lower right-hand side of the region depicted, which shows evidence of carbonation.
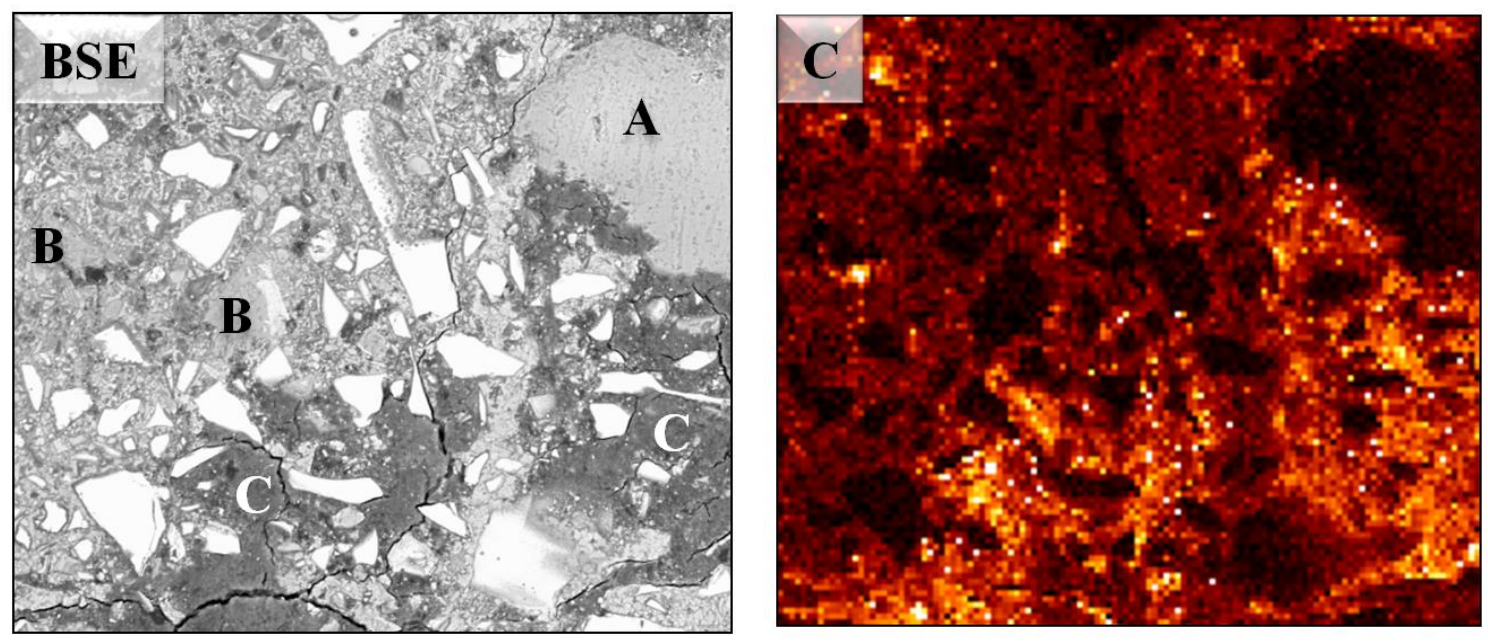

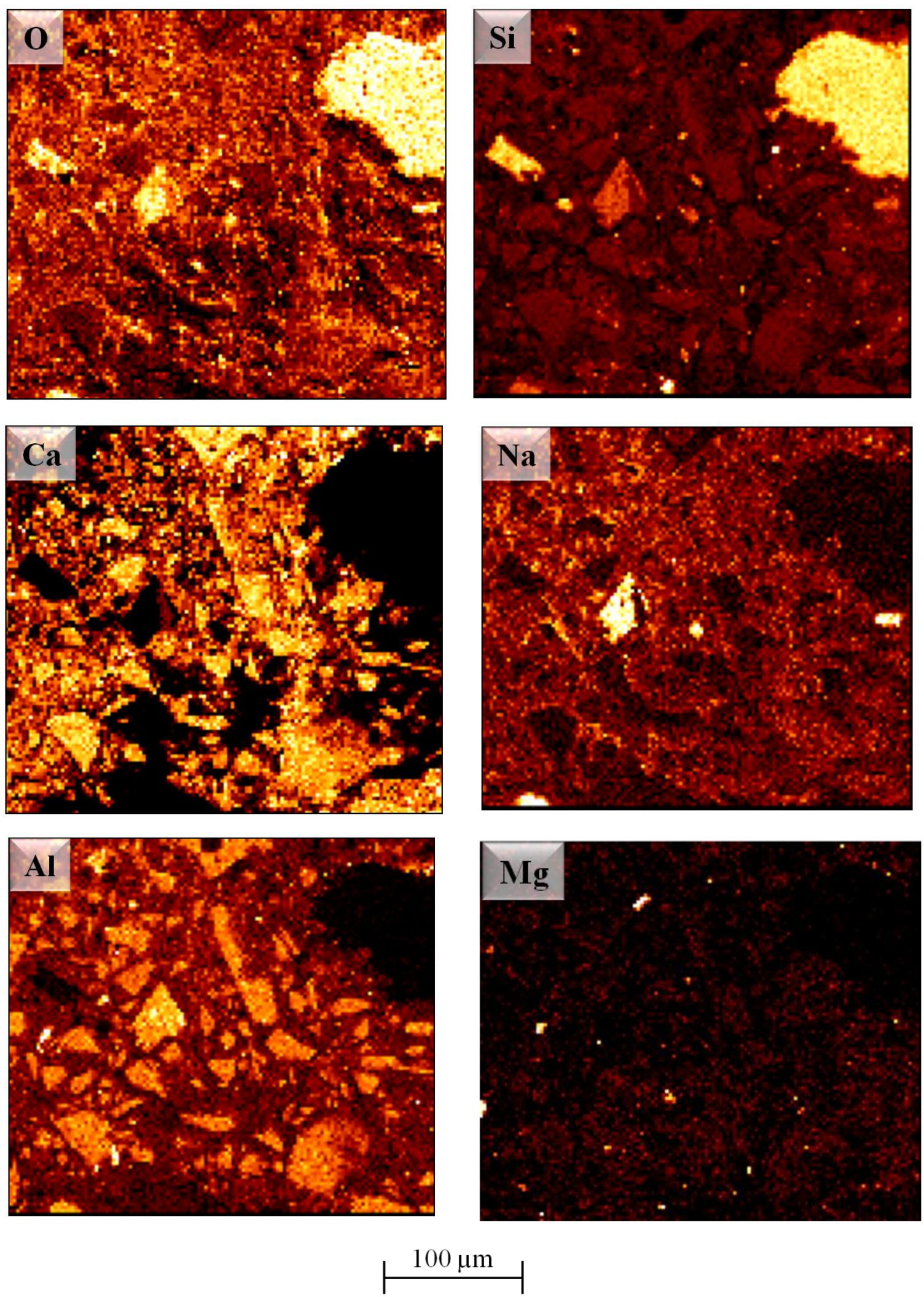

Low

High 
Figure 8. Backscattered electron image of a region close to the interface between carbonated and uncarbonated regions according to the phenolphthalein test, and elemental maps of $400 \mathrm{~kg} / \mathrm{m}^{3}$ slag concrete activated at 4 wt. $\% \mathrm{Na}_{2} \mathrm{O}, \mathrm{Ms}=1.3$ and w/b 0.42. The elemental maps show the same region as the backscattered electron image.

Although carbonated regions can be identified in the concretes, as in Figure 8, it was not possible to determine the depth of carbonation via ESEM. A clear and distinct carbonation front could not be observed in these specimens; instead, it appears that preferentially formed carbonated regions are identified in areas where microcracks are present. The microcracking identified in partially carbonated activated slag concretes may be associated with the autogenous shrinkage of the samples over time of reaction, as discussed above, which would favor the ingress of $\mathrm{CO}_{2}$ into the specimens and promote the carbonation of the binding gel. However, it is also possible that this is a consequence of the decalcification of the binding gel, which induces internal mechanical stresses and promotes the formation of microcracks during carbonation [36]. It is not possible at this point to distinguish which mechanism is governing this phenomenon, or if both are occurring simultaneously, but this is certainly an area worthy of further study.

A higher magnification ESEM image of a carbonated paste region in a concrete specimen is shown in Figure 9, where microcracking throughout the decalcified gel can be observed, and the damage to the binding gel is evident. This is consistent with the increased permeability of alkali-activated slag concretes subjected to accelerated carbonation [20], and the reduced mechanical strength reported in carbonated specimens [10]. 


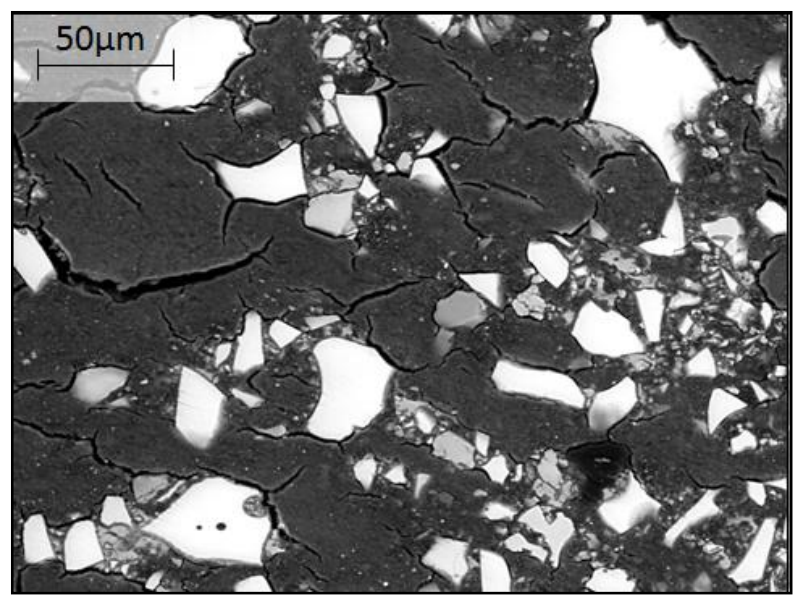

Figure 9. Backscattered electron image of a fully carbonated region in the $400 \mathrm{~kg} / \mathrm{m}^{3}$ slag concrete, activated at 4 wt. $\% \mathrm{Na}_{2} \mathrm{O}, \mathrm{Ms}=1.3$ and w/b 0.48 .

In some regions, a highly dense intermixing of binding gel and carbonation products is also observed (Figure 10). In the binding gel surrounding the aggregates (point A) lower $\mathrm{C}$ and $\mathrm{O}$ concentrations are identified, when compared with the dark gray regions (B and C). The dark gray paste formed between two aggregate particles (B) shows a slight reduction in the $\mathrm{Ca}$ concentration along with an increment in $\mathrm{C}$ and $\mathrm{O}$ concentrations, consistent with the partial carbonation of this gel. Point $\mathrm{C}$ in Figure 11 shows higher concentrations of $\mathrm{C}$ and $\mathrm{O}$ than the other regions analyzed, and it is identified as completely carbonated paste. In these regions, it is not possible to identify microcracks throughout the carbonated gel, which may suggest that carbonation is promoting the formation of significant microcracks in the bulk paste region shown in Figure 10, but that it does not induce the intensive formation of cracks that can be observed at the lower magnification shown in Figure 11 in the gels immediately surrounding the aggregates. This observation necessitates some analysis of the differences between bulk and interfacial transition zone paste microstructures in these concretes. 


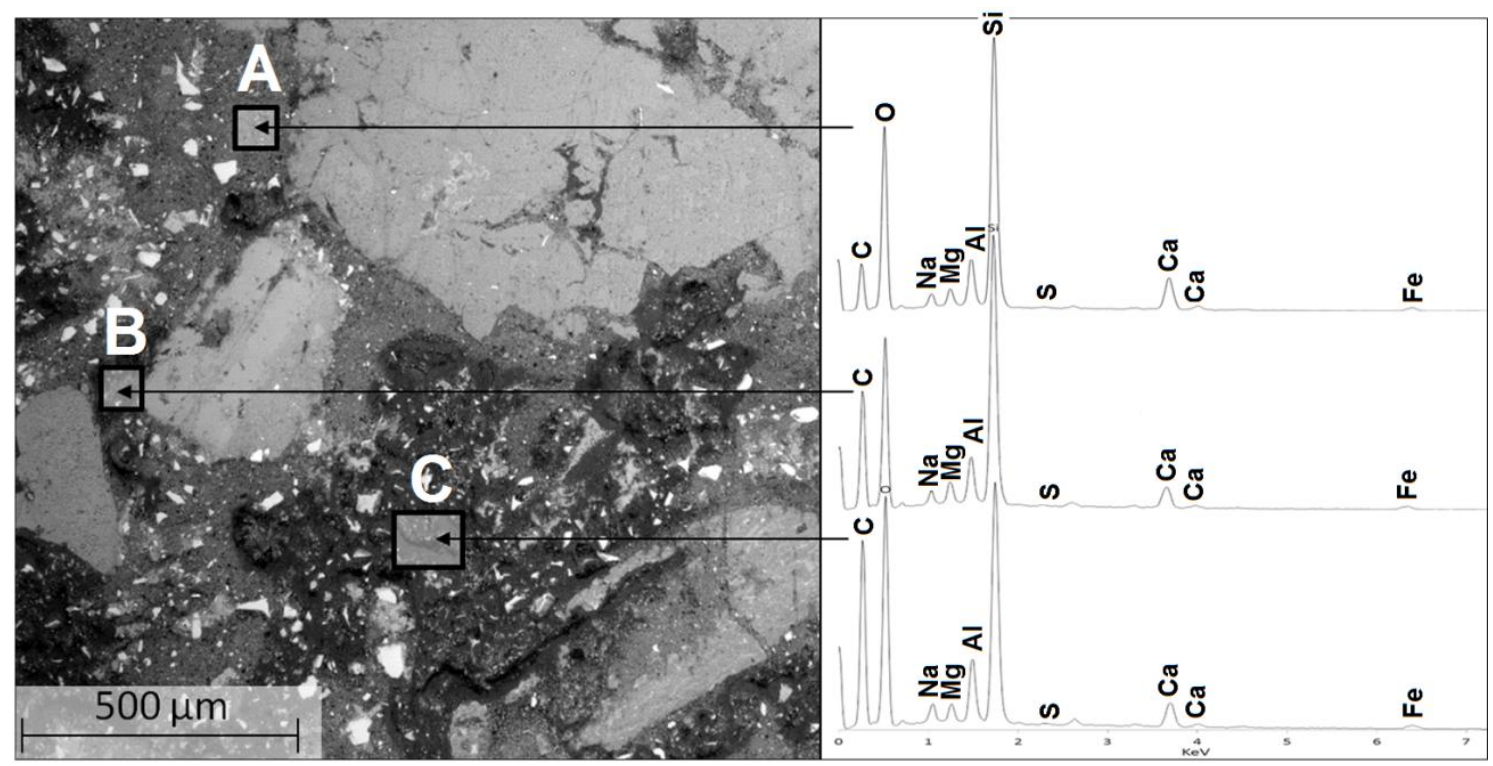

Figure 10. Backscattered electron image of $400 \mathrm{~kg} / \mathrm{m}^{3}$ slag concrete activated at 4 wt. $\% \mathrm{Na}_{2} \mathrm{O}$, and EDX spectra of each of the regions identified in the micrograph

Figure 11 shows a higher-resolution BSE image and selected EDX spectra for another interfacial region, displaying both ITZ and bulk binder regions. Decalcification of the binding gel formed in the ITZ is not observed in Figure 11, consistent with Figure 10, and providing evidence of the high stability and low permeability of this region in alkali-activated slag concretes.

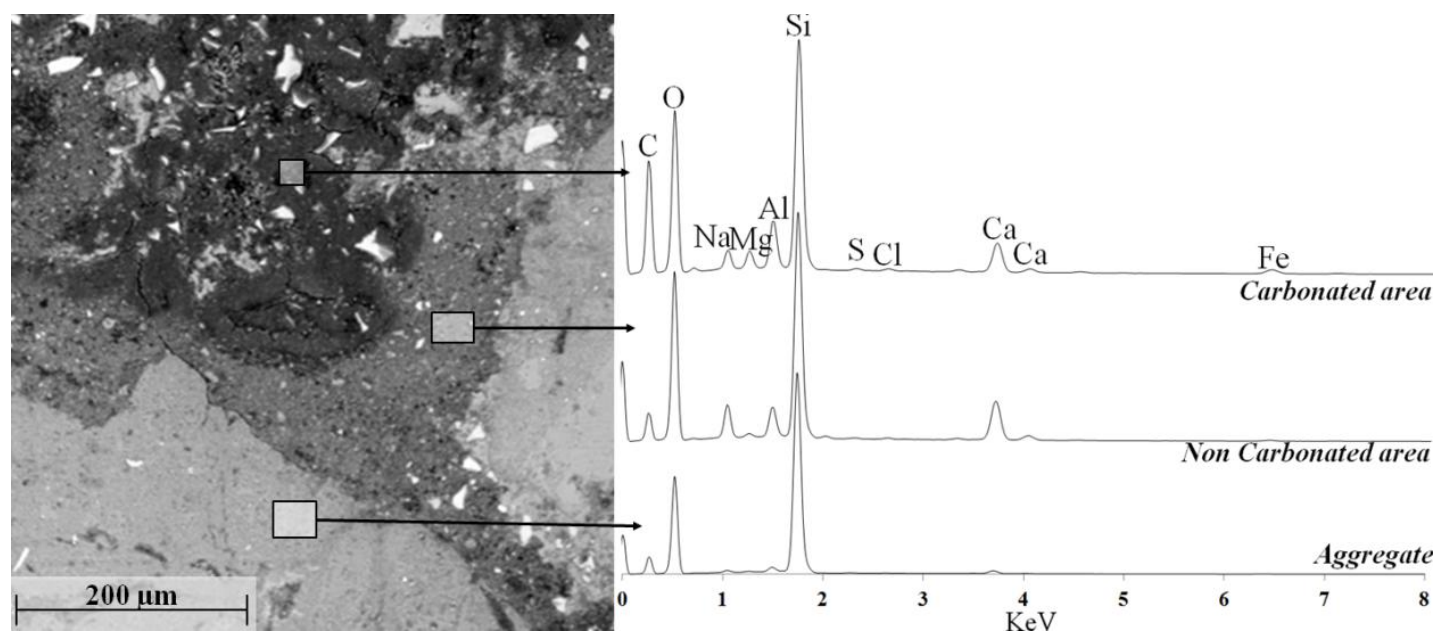

Figure 11. Backscattered electron image of $400 \mathrm{~kg} / \mathrm{m}^{3}$ slag concrete activated at 4 wt. $\% \mathrm{Na}_{2} \mathrm{O}$, and EDX spectra of each of the regions identified in the micrograph 
Summary plots of EDX results of carbonated and uncarbonated gels in all of the concretes studied are shown in Figure 12. Comparable $\mathrm{Ca} / \mathrm{Si}$ and $\mathrm{Al} / \mathrm{Si}$ ratios are identified in all uncarbonated concrete pastes, even though different activation conditions and w/b ratios were used to produce these binders (Table 2). The $\mathrm{Ca} / \mathrm{Si}$ ratios are relatively low (between $0.5-0.8)$, attributed to the progressive formation of $(\mathrm{C}, \mathrm{N})$ A-S-H type gels at advanced times of curing. In all cases carbonation induces the reduction of both $\mathrm{Ca} / \mathrm{Si}$ and $\mathrm{Al} / \mathrm{Si}$ ratios of the paste, as previously identified in alkaliactivated slag pastes subjected to accelerated carbonation [29]. A higher degree of dispersion in the $\mathrm{Ca} / \mathrm{Si}$ ratios is observed in pastes extracted from concretes formulated with 5 wt.\% $\mathrm{Na}_{2} \mathrm{O}$ at both w/b ratios in this study, which indicates that the higher activator dose is favoring the formation of C-A-S-H type gels with different $\mathrm{Ca} / \mathrm{Si}$ ratios, associated with the potential inclusion of higher concentrations of $\mathrm{Na}$ in the binding gel.

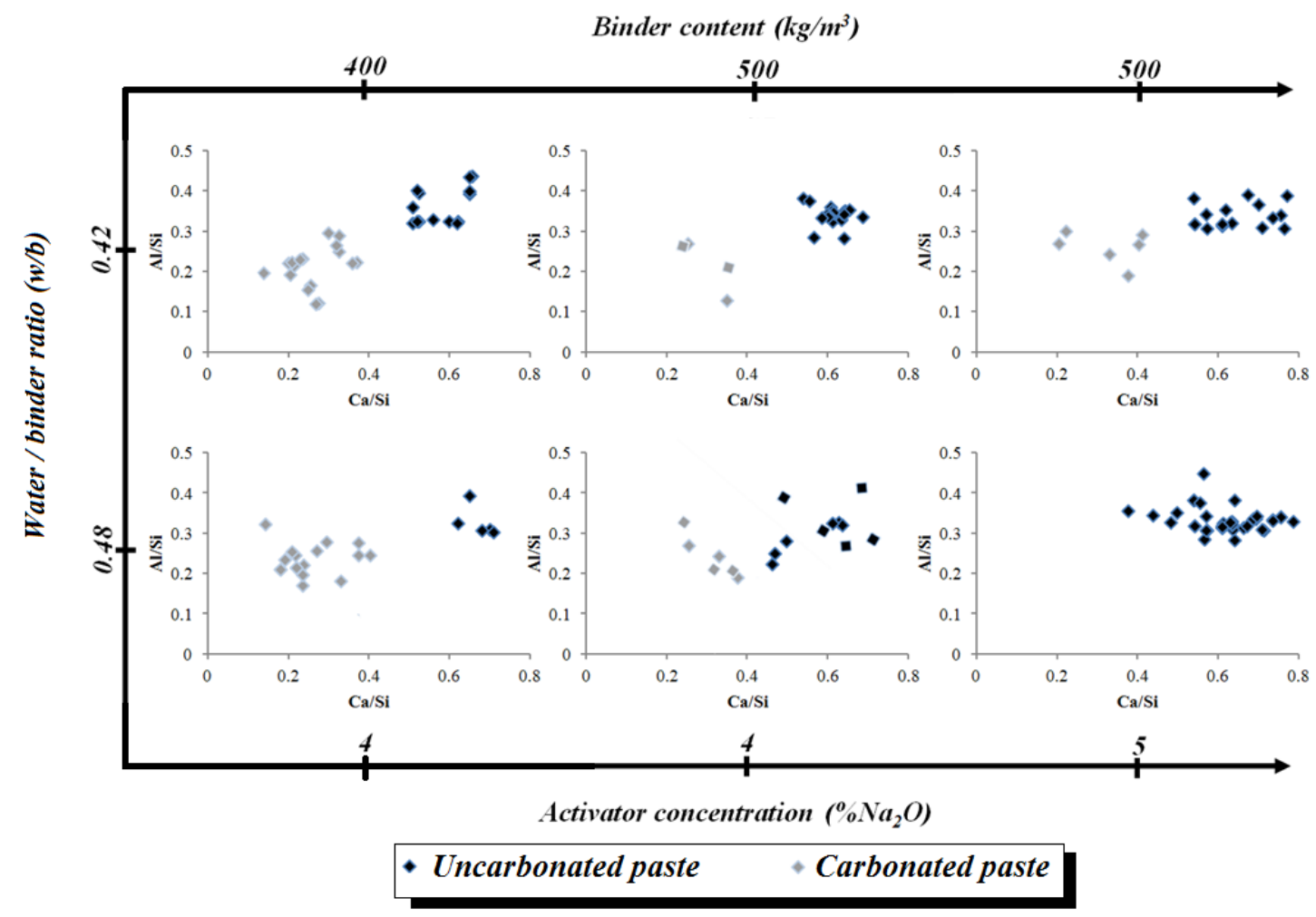

Figure 12. Summary of the atomic ratios $\mathrm{Ca} / \mathrm{Si}$ vs $\mathrm{Al} / \mathrm{Si}$ (between 6 and 20 measurements per specimen) for uncarbonated and carbonated regions of aged alkaliactivated slag concretes. No carbonated regions were identifiable by SEM-EDX 
analysis in the concrete with $500 \mathrm{~kg} / \mathrm{m}^{3}$ slag, $5 \mathrm{wt} . \% \mathrm{Na}_{2} \mathrm{O}$ and water/binder $=0.48$, so no data for such regions are plotted for this sample.

\section{Conclusions}

The depth of carbonation observed in aged alkali-activated slag concretes formulated with $400 \mathrm{~kg} / \mathrm{m}^{3}$ of slag exposed to the ambient environment for 7 years is much lower than would be predicted through accelerated carbonation testing, demonstrating that the exposure conditions used in accelerated testing do not replicate the phenomena that take place under natural service conditions. This is attributed in large part to the thermodynamic differences between accelerated and natural carbonation conditions, which lead to different processes controlling the carbonation rates observed under different conditions, and meaning that even the ranking order of different samples in terms of carbonation rates will differ between accelerated and in-service conditions. The activator and slag contents seems to be the main factor determining the mechanical and water absorption properties of activated slag concretes during the first 180 days of curing, as negligible differences are identified when concretes are formulated with different water/binder ratios. Materials with similar formulations and different water/binder ratios also show equivalent carbonation depths. Increasing the paste volume to $500 \mathrm{~kg} / \mathrm{m}^{3}$ does not necessarily give a reduction in carbonation rates, as microcracking and self-dessication effects can sometimes become more significant in these mixes.

The main products of natural carbonation of alkali-activated slag concrete are calcite and vaterite, derived from the decalcification of the binding gel, along with the sodium carbonates natron and trona associated with the carbonation of the pore solution. The bicarbonate phase nahcolite, which is generated during accelerated carbonation testing, is not observed under natural conditions. Formation of the mixed $\mathrm{Na}-\mathrm{Ca}$ carbonate phase nyerereite is observed in concretes formulated at higher activator concentration, indicating the development of a highly self-desiccating environment within the material, 
consistent with the increased scope for water ingress and increased carbonation depth identified in those concretes.

Carbonation in aged alkali-activated slag concretes does not take place as a distinctive front, and does not appear to take place in specific regions (e.g. interfacial transition zones) within the material. Preferential carbonation of this gel was not detected in any of the concretes assessed, demonstrating that the ITZ is the region least susceptible to carbonation in alkali-activated slag concretes, conversely to the identified in conventional Portland cement concretes.

These results provide a detailed and deeper understanding of the natural process of carbonation in alkali-activated slag concretes, and the high structural stability and durability of these materials in service, which seems to improve over time as the microstructure and binder become more mature.

\section{Acknowledgments}

This study was sponsored by the Australian Research Council (ARC) through a linkage grant between University of Melbourne and Zeobond Pty, including partial funding through the Particulate Fluids Processing Centre, a Special Research Centre of the ARC. The participation of R. Mejía de Gutiérrez was funded by Universidad del Valle (Colombia) and the GEOCERAM Project. The authors would like to express their gratitude to William Valencia and Jherson Díaz (Univalle) for carbonation depth data collection, and Brant Walkley (UniMelb) for his assistance in the difficult task of obtaining the carbonated paste from the hardened concretes for the XRD analysis.

\section{References}

1. Juenger MCG, Winnefeld F, Provis JL, Ideker JH (2011) Advances in alternative cementitious binders. Cement and Concrete Research 41(12): 12321243. 
2. van Deventer JSJ, Provis JL, Duxson P (2012) Technical and commercial progress in the adoption of geopolymer cement. Minerals Engineering 29: 89104.

3. Wang S-D, Pu X-C, Scrivener KL, Pratt PL (1995) Alkali-activated slag cement and concrete: a review of properties and problems. Advances in Cement Research 7(27): 93-102.

4. Talling B, Krivenko PV. Blast furnace slag - The ultimate binder. In: Chandra S, Waste Materials Used in Concrete Manufacturing, Noyes Publications, Park Ridge, NJ. 1997, p. 235-289.

5. Roy D (1999) Alkali-activated cements - Opportunities and challenges. Cement and Concrete Research 29(2): 249-254.

6. Shi C, Krivenko PV, Roy DM. Alkali-Activated Cements and Concretes, Abingdon, UK: Taylor \& Francis, 2006.

7. van Deventer JSJ, Provis JL, Duxson P, Brice DG (2010) Chemical research and climate change as drivers in the commercial adoption of alkali activated materials. Waste and Biomass Valorization 1(1): 145-155.

8. Puertas F, Palacios M, Vázquez T (2006) Carbonation process of alkaliactivated slag mortars. Journal of Materials Science 41: 3071-3082.

9. Palacios M, Puertas F (2006) Effect of carbonation on alkali-activated slag paste. Journal of the American Ceramic Society 89(10): 3211-3221.

10. Bernal SA, Mejía de Gutierrez R, Rose V, Provis JL (2010) Effect of silicate modulus and metakaolin incorporation on the carbonation of alkali silicateactivated slags. Cement and Concrete Research 40(6): 898-907.

11. Bernal SA, Mejía de Gutierrez R, Pedraza AL, Provis JL, Rodríguez ED, Delvasto S (2011) Effect of binder content on the performance of alkaliactivated slag concretes. Cement and Concrete Research 41(1): 1-8.

12. Papadakis VG, Vayenas CG, Fardis MN (1991) Experimental investigation and mathematical modeling of the concrete carbonation problem. Chemical Engineering Science 46: 1333-1338.

13. Hobbs DW (2001) Concrete deterioration: causes, diagnosis, and minimising risk. International Materials Reviews 46(3): 117-144.

14. Johannesson B, Utgenannt P (2001) Microstructural changes caused by carbonation of cement mortar. Cement and Concrete Research 31: 925-931.

15. Steffens A (2002) Modeling carbonation for corrosion risk prediction of concrete structures. Cement and Concrete Research 32: 938-941. 
16. Glasser FP, Marchand J, Samson E (2008) Durability of concrete Degradation phenomena involving detrimental chemical reactions. Cement and Concrete Research 38(2): 226-246.

17. Poonguzhali A, Shaikh H, Dayal RK, Khatak HS (2008) Degradation mechanism and life estimation of civil structures - A review. Corrosion Reviews 26(4): 215-294.

18. Deja J (2002) Carbonation aspects of alkali activated slag mortars and concretes. Silicates Industriels 67(1): 37-42.

19. Xu H, Provis JL, van Deventer JSJ, Krivenko PV (2008) Characterization of aged slag concretes. ACI Materials Journal 105(2): 131-139.

20. Bernal SA, Mejía de Gutierrez R, Provis JL. Carbonation of alkali-activated GBFS-MK concretes. In: Justnes H, Jacobsen S, Cepuritis R, Hornbostel K, Peng Y, eds. International Congress on Durability of Concrete. Trondheim, Norway, Norsk Betongforening, 2012. CD-ROM.

21. Bernal SA, Provis JL, Brice DG, Kilcullen A, Duxson P, van Deventer JSJ (2012) Accelerated carbonation testing of alkali-activated binders significantly underestimate the real service life: The role of the pore solution. Cement and Concrete Research 42(10): 1317-1326.

22. Hewlett PC. Lea's Chemistry of Cement and Concrete, 4th Ed., Oxford, UK: Elsevier, 1998.

23. Ho DWS, Lewis RK (1987) Carbonation of concrete and its prediction. Cement and Concrete Research 17(3): 489-504.

24. Lloyd RR, Provis JL, van Deventer JSJ (2010) Pore solution composition and alkali diffusion in inorganic polymer cement. Cement and Concrete Research 40(9): 1386-1392.

25. Greenwood K, Pearce M (1953) The removal of carbon dioxide from atmospheric air by scrubbing with caustic soda in packed towers. Transactions of the Institution of Chemical Engineers 31: 201-207.

26. Bernal SA, Provis JL, Mejía de Gutierrez R, Rose V (2011) Evolution of binder structure in sodium silicate-activated slag-metakaolin blends. Cement and Concrete Composites 33(1): 46-54.

27. Melo Neto AA, Cincotto MA, Repette W (2008) Drying and autogenous shrinkage of pastes and mortars with activated slag cement. Cement and Concrete Research 38: 565-574.

28. de Castro A, Ferreira R, Lopes AM, Cascudo O, Carasek H. Relationship between results of accelerated and natural carbonation in various concretes. In: Vázquez E, Hendriks CF, Janssen GMT, eds. International RILEM Conference 
on the Use of Recycled Materials in Building and Structures. Barcelona, Spain, RILEM Publications, 2004. 988-997.

29. Bernal SA, Provis JL, Walkley B, San Nicolas R, Gehman JD, Brice DG, Kilcullen AR, Duxson P, van Deventer JSJ (2013) Gel nanostructure in alkaliactivated binders based on slag and fly ash, and effects of accelerated carbonation. Cement and Concrete Research: Submitted.

30. Bernal SA, Provis JL, Rose V, Mejía de Gutiérrez R (2013) High-resolution Xray diffraction and fluorescence microscopy characterization of alkali-activated slag-metakaolin binders. Journal of American Ceramic Society, In press, DOI: 10.1111/jace. 12247 .

31. Albert BR, Cheetham AK (2000) A synchrotron X-ray powder diffraction study of highly crystalline low-silica zeolite $\mathrm{P}$ during $\mathrm{Na}-\mathrm{Ca}$ ion exchange. Microporous and Mesoporous Materials 34(2): 207-211.

32. Stepkowska ET, Aviles MA, Blanes JM, Pérez-Rodríguez JL (2007) Gradual transformation of $\mathrm{Ca}(\mathrm{OH})_{2}$ into $\mathrm{CaCO}_{3}$ on cement hydration. XRD study. Journal of Thermal Analysis and Calorimetry 87(1): 189-198.

33. Eugster HP (1966) Sodium carbonate-bicarbonate minerals as indicators of $\mathrm{P}_{\mathrm{CO} 2}$. Journal of Geophysical Research 71(14): 3369-3377.

34. Zaitsev AN, Keller J, Spratt J, Perova EN, Kearsley A (2008) Nyerereite pirsonnite - calcite - shortite relationships in altered natrocarbonatites, oldoinyo lengai, Tanzania. Canadian Mineralogist 46: 483-860.

35. Dheilly R-M, Tudo J (1997) Contribution à létude de la gaylussite: $\mathrm{Na}_{2} \mathrm{Ca}\left(\mathrm{CO}_{3}\right)_{2}, 5 \mathrm{H}_{2} \mathrm{O}$. Comptes Rendus de l'Académie des Sciences - Series IIB Mechanics-Physics-Chemistry-Astronomy 325(7): 407-414.

36. Chen JJ, Thomas JJ, Jennings HM (2006) Decalcification shrinkage of cement paste. Cement and Concrete Research 36(5): 801-809.

We thank the reviewers for their valuable comments and suggestions on our manuscript, which contribute to the improvement of the paper. We have made revisions considering to these comments. The reviewer comments are reproduced here in bold italics, with our responses in plain text.

Reviewer \#1: The originality of the paper is its strongest point. However, the conclusions and new contributions to understand the carbonation phenomena in alkali activated slag are too weak for a scientific research paper. This paper may be appropriate for a publication as a technical note since the amount of meaningful data presented is small. 
We disagree with the reviewer regarding the lack of new contributions. Our manuscript is the first systematic study to explain the effect of different activation conditions on the structural development of aged alkali-activated slag concretes, and on the phases that are forming upon natural carbonation of these materials. Also, we compare our results with those obtained in accelerated carbonation testing of similar materials, so that we are elucidating some of the factors controlling the rate and mechanism of carbonation under accelerated and natural conditions in alkali-activated concretes. This is far beyond the scope of a technical note.

Carbonation is a degradation mechanism that is not well understood even for conventional cements, where a relatively good understanding of the chemistry has been achieved. In alkali-activated systems, we face the challenge that the chemistry of the reaction products and pore solution is completely different from the Portland cement systems which are best described in the literature. Therefore, the approach we have followed to examine these aged concretes is the most suitable for understanding the interaction of activated concretes and their environment, based on the limited availability of detailed information for these materials.

It is impossible, in a single manuscript, to solve all the questions about carbonation of alkali-activated materials. However, in this manuscript we are showing the remarkable differences in the microstructures of aged concretes, bringing a better picture about what needs to be replicated under accelerated conditions in order to test the real susceptibility of these materials to decay due to carbonation. We feel that this is an extremely important aim for a manuscript, and is addressed directly in the work presented here.

1- The introduction to the paper is poorly written. The discussions of prior research work are not well done. The relationship to the current work is not clear. A lot of important details are missed which makes it difficult to draw conclusions from the cited work. The way that is written now is misleading since the manner that facts are described makes it clearly difficult to see any new outcome from the actual study. 
In the introduction section, we review all of the available relevant literature regarding carbonation and alkali-activation, to support and highlight the work developed in this manuscript; the previous results available have been clearly described and discussed to provide context for our work. The reviewer needs to keep in mind that the volume of literature available about carbonation of activated binders is very low (there are only 8 papers published in this area to date), and these phenomena are being analysed in detail for the first time by the authors of the present manuscript, in a series of recent publications. Analysis of the phases forming in aged carbonated alkali-activated concretes has never been conducted before, and therefore, the detailed analysis of our samples is a new outcome on its own.

2- The experimental part is not really well written. There are a lot of missed details that may help to understand the different steps of the study. Nothing really new can come out from the paper or what is new is not really shown in a good way. The authors should write their experimental part with regard to the results that they show to make the reading easy.

We disagree with the comment that the experimental program is not well written; nonetheless, we have clarified and extended this section in the revised manuscript as detailed in the response to the specific reviewer comments below. The only significant missing information was the detailed formulation of the concretes assessed, which is included in the revised version of the manuscript.

The experimental program is already presented considering the results presented and discussed in the manuscript, and we cannot identify the difficulties the reviewer is pointing out that make reading so difficult.

3 - The framework of the experiments here makes the task difficult to define a real approach for the understanding of the carbonation process under the natural weathering conditions. The results presented here appear without requested 
discussions to be more an arbitrary speculation than objective information (the word surprisingly has its place in patent and not in a scientific work).

The word 'surprisingly' has been removed from the manuscript, as suggested by the reviewer.

Please see my comments on your paper...

A1 - Already stated in the beginning of the paragraph!

This line has been removed from the abstract

A2 - Which physical properties? The carbonation berely affects the OPC phydical properties.. it is however more harmful for steell

By physical properties we mean 'permeability', and this is now stated explicitly here. We disagree with the reviewer that carbonation 'barely' affects OPC, because carbonation, as the chemical reaction between $\mathrm{CO}_{2}$ and the $\mathrm{Ca}(\mathrm{OH})_{2}$ and $\mathrm{C}-\mathrm{S}-\mathrm{H}$ in conventional Portland cements, or $\mathrm{CO}_{2}$ and $\mathrm{C}-\mathrm{A}-\mathrm{S}-\mathrm{H}$ in blended Portland cements, induces changes in the porosity of the material, and therefore their density. The carbonation reaction itself is not harmful for steel, the key point is the reduction in the $\mathrm{pH}$ led by carbonation, causing depassivation of the steel reinforcement which makes the steel susceptible to corrosion, especially in the presence of chlorides.

\section{A3 - Are you sure that we use wastes? I prefer to limit it to industrial by-products}

We have changed the terminology here to refer only to by-products, as requested.

A4 - Depending on the activator used, curing temperature and the type of slag used as well

We agree with this comment, and it has been included in the manuscript.

A5 - This is not the only issue, health and safety issues as well are another problem 
We agree with the reviewer; that is why we say it is $\underline{a}$ key issue, not the only issue, which must be addressed to increase the confidence and acceptance of these alternative materials.

\section{A6 - Do you mean $\mathrm{pH}$}

Not necessary just $\mathrm{pH}$, also availability of $\mathrm{Na}^{+}$and hydroxide in the pore solution (e.g. through buffering by silicate anion protonation equilibria), which plays an important role in how carbonation proceeds in alkali-activated materials, as described, observed and modelled in detail in our paper cited as ref. 21 ([1])

\section{A7 - I do not see really the link in OPC}

We are describing what happens in alkali-activated materials, not OPC, and the carbonation mechanisms are very different. In activated slag binders formation of portlandite is not identified, therefore the $\mathrm{CO}_{2}$ directly reacts with the alkalis in pore solution and the C-A-S-H phase formed in the binder system to form sodium-rich and calcium-rich carbonates, which is why carbonation leads to reductions in the mechanical strength of these materials.

\section{A8 - I think that is the same for all cementitious systems with reduced W/B ratio}

We agree with this when talking about Portland cement based materials. The issue here is that alkali-activated materials carbonate very quickly under accelerated carbonation conditions, and it has been claimed that they will perform badly when exposed to $\mathrm{CO}_{2}$. In this paragraph we are highlighting that this is not true for alkali-activated concretes in service as carbonation rates of 1 $\mathrm{mm} /$ year (comparable to what it will be expected in a Portland cement) have been identified in activated concretes, in contrast to the predictions from accelerated carbonation testing, as mentioned at the start of the paragraph.

\section{A9 - I do not agree! Don't you think that is more related to the porosity and available water in pore solution rather than to the nature of formed hydrates?}

These factors will also affect carbonation rates. However, in a recent publication by the authors [1] we have shown experimental and theoretical evidence that different accelerated conditions lead to the formation of different types of carbonation products in alkali-activated binders, and a 2-unit difference in $\mathrm{pH}$ between accelerated and natural conditions, which drives the carbonation mechanism in different directions. Another study conducted by the authors [2] shows how a diffusion controlled mechanism is not sufficient to describe the carbonation rate of alkali-activated materials, highlighting that a chemical controlling mechanism is more suitable to describe this phenomena in alkali activated binders.

It is important also to mention that alkali-activated concretes usually report low permeability and are in many cases produced with low w/b ratios, presenting a highly tortuous pore network [3], and therefore carbonation cannot be considered as a mechanism solely driven by transport/diffusion mechanisms.

A10- It does not make 100\% which other elements did you observe? 
This has been corrected in the manuscript

\section{A11 - Sodium metasilicate}

We didn't use sodium metasilicate (defined as being modulus 1.0) as activator, we used highermodulus solutions of sodium silicate that are also commercially available, as described correctly in the manuscript text.

\section{A12 - Is it really needed to have such high $\mathrm{Na2O}$}

Yes it is needed, that is the fundamental concept of alkali-activation. An increased alkalinity is required to promote the dissolution of the slag and subsequent polycondensation of reaction products. Each slag will need different concentrations to achieve effective activation, and for the specific slag used in this study, detailed information about effect of activation conditions in fresh properties and structural evolution is given in [4].

\section{A13 - Please be more specific by reporting the exact amount of $\mathrm{NaOH}$ and sodium} metasilicate and added water.. it is easier to follow for the reader

Detailed formulation information for the concretes is now given in the paper.

\section{A14 - Why this curing mode? Does the $100^{\circ} \mathrm{C}$ not decompose your C-S-H partially?}

We thank the reviewer for identifying that this sentence was not worded clearly - this was the pre-conditioning of the samples for the test method, not the curing temperature. This has been corrected and clarified in the manuscript. $100^{\circ} \mathrm{C}$ was used for the testing because this is what is specified in the ASTM C 642-06 testing procedure.

A15 - It is too short to see any carbonation especially with the natural conditions of storage and open laboratory facility.. it would be better to store them in a road where there is a lot of traffic...

Before carrying out the detailed analysis of the concretes, samples were taken and characterised to ascertain that a carbonated layer had indeed been formed, as this was the main goal of our study. The samples were not indoors, the specimens were kept in the roof of a lab facility in front of the main open car-park of the University. This information has been included in the manuscript for further clarification.

A16 - Actually with these range of values no samples will carbonate as the concentration is really low...

Natural carbonation of conventional Portland-cement concretes has been observed at this concentration as reported by Sanjuan et al. [5] in a shorter period of exposure (2 years) than the assessed here. Considering the increased alkalinity of our concretes (and differences in chemistry when compared with Portland cement), it was expected that we would see signs of carbonation after 7 years of curing.

A17 - Do you think that it is an adequate method as with your Na2O level you will have always a pH above 13.5 and phenolphthalein reacts mainly to the $\mathrm{pH}$.

We are aware that the phenolphthalein method is not the most reliable to assess 'carbonation' of alkali-activated materials, but neither is it necessarily ideal for assessing carbonation of blended cements, as portlandite is consumed during the pozzolanic reaction. 
In our case we cannot correlate consumption of portlandite with the extent of the carbonation reaction, as is the case for Portland cements, because we do not form portlandite as a reaction product; however, the change in $\mathrm{pH}$ is indicating to us that most of the alkalis in the pore solution are carbonated, and therefore the $\mathrm{CO}_{2}$ is reaching the $\mathrm{C}-\mathrm{S}-\mathrm{H}$ to promote the formation of calcium carbonates. So, it appears that the carbonation front as measured by a careful and reproducible application of phenolphthalein solution does provide a relatively representative measure of the actual $\mathrm{CO}_{2}$ ingress into these samples. We have tested a variety of different $\mathrm{pH}$ indicators and other methods of carbonation front determination in our laboratory during the past several years, and have not yet found a method which is more reproducible or reliable than this standard, well-accepted method, if it is applied consistently and with care.

\section{A18 - How carefully extracted...}

Different slices of a cylinder were cut and the sprayed with phenolphthalein to identify the changes in the $\mathrm{pH}$ and the regions where carbonation was occurring. Once the carbonation depth was determined, a cant saw file was used to remove mortar samples from the concrete, which were sieved to remove sand particles and washed in acetone before analysing them via XRD.

This information has been included in the manuscript for further clarification.

A19 - What do you mean by physical features? Porosity, cracking, etc.. please be more precise Everything described by the reviewer is considered a physical feature. We have followed this suggestion in the manuscript

\section{A20 - Which standard was used to calibrate the SEM and how do you get a reasonable} information about $C$

Details of the analyses and acquisition mode have been added to the paper. The modern systems used in the Bio21 Institute, University of Melbourne (the facility used for collecting the ESEM/EDX results reported in this manuscript) calculate standard quantification based on very careful calibration in the factory with a matrix of elemental standards.

We are aware that several parameters can influence the carbon mapping such as the roughness of the sample or the pressure; however, the analysis of pure calcium carbonate has been run to control the level of carbon measured by our instrument under the same experimental conditions we used in this study. Our results show a difference of 
the carbon content of $0.3 \mathrm{wt} . \%$ of the stoichiometric composition of pure $\mathrm{CaCO}_{3}$. The topography of the samples was also imaged in secondary electron mode before any acquisition of BSE images, to ensure flatness of the area studied and thus reduce the error induced by the roughness of the sample.

\section{A21 - No influence of the Na2O.. do you have any explanation for that}

Detailed analysis of samples formulated with different concentrations of activation with this specific slag have not yet been conducted at such extended ages of curing, so we cannot attribute this phenomenon to the formation of a particular microstructure, or to the content of binder in the concrete independent of the activation conditions. We prefer not to speculate in this regard in the current manuscript, but are continuing our detailed and systematic analysis of aged concrete samples to try to answer questions such as this in future.

A22 - I am not sure of this statement as your results show no influence of the alkali level at relatively higher $W / B$ ratio

We agree with the reviewer, this is more likely a porosity effect. This has been removed from the manuscript.

A23 - No.. your results show something different.

We think that the VPV values are comparable but we are not saying they are the same. We have changed 'similar' to 'comparable' here.

\section{A24 - Are you sure? Use the same w/B ratio used during this study for Portland cement concrete and you will have better results}

The reviewer appears to have misunderstood the manuscript here - we are saying that Portland cement concrete does show a strong influence of w/b ratio on porosity (as evidenced by an extensive body of literature), whereas these alkali-activated concretes do not, within the range studied. 
A25 - This is not anymore surprising.. try $a$ W/B ratio of 0,55 and you will be more surprised by the drop of strength and how much porosity you will have in comparison to OPC

As mentioned above, the word 'surprising' has been removed from the manuscript. We appreciate the comments from the reviewer, but conducting additional experiments to prove agreement with his/her understanding of Portland cement systems is out of the scope of the present manuscript. We have added the note 'within the range studied' parenthetically in this paragraph to address this comment.

A26 - As stated before not anymore surprising. When you used low W/B ratio you form a matrix more or less like ceramics.. the extent of your reaction will be related to the available water and thus low porosity will be all the time observed

We agree with the reviewer; however, this comment does not lead to any changes to the manuscript

A27 - With the actual $w / b$ ratio, I totally agree.. Use higher $w / b$ ratio and you will be more suprised

See responses above. This point, while probably true, is also not particularly relevant to the argument here.

A28 - Only speculation.. did you perform any measurement on the composition of the pore solution and how the alkali are bound to the hydrates? Did you perform any mass balance of the different elements?

This discussion is based on the known higher $\mathrm{Na}^{+}$concentration of alkali-activated binders formulated with increased $\mathrm{Na}_{2} \mathrm{O}$ content [6], as well as the widely known fact that higher concentrations of alkali hydroxide solutions absorb $\mathrm{CO}_{2}$ more effectively from the atmosphere. This information has been included in the manuscript in addition to a citation to a seminal paper in the area, [7], which is now cited as ref. 24 in the manuscript.

We have actually conducted studies regarding the incorporation of alkalis into the C-A$\mathrm{S}-\mathrm{H}$ products forming in activated binders, as shown in some recent publications of the 
authors $[8,9]$; however, detailed analysis of the alkali binding to the hydrates and mass balances of different elements have not been conducted as this is not within the scope of the present study.

A29 - These results are more relevant and of course at 28 days the porosity of your sample is still open...

We disagree with the reviewer that these results are 'more relevant' - they provide some additional information, but the very significant structural changes which are well known to take place in alkali-activated concretes between 28 days and several years of age mean that the samples studied at both ages are valuable. It is therefore important to understand what happens in both situations, to be able to identify a good method for assessing this phenomenon.

\section{A30 - Do you mean that alkali activated other ways of testing the sampels?}

We do not understand what this comment means

\section{A31 - You could perorm TGA at different depth if you are able to extract the paste carefully.}

We are aware that this method has been usefully used before, but considering the fairly low carbonation depths identified in our concretes, it proved impossible to extract reliable samples from specific depths without interference from fine aggregate fragments. This is why we preferred to examine the samples via ESEM; the TGA analysis of such samples could not be considered useful in any sort of quantitative way.

A32 - Please remove this part. it is only to fill in paper without any additional scientific information 
We disagree with the reviewer. We believe this is an important point to address in this study as it explains how activation conditions and formulation of the concretes play a significant role in microcracking, which is one of the factors that can most affect the results of any durability testing of alkali-activated materials, as transport properties will be different in systems more prone to self-dessication. Therefore, this is a relevant piece of scientific information that needs to be kept in mind when designing and analysing testing methods for alkali-activated materials.

\section{A33 - How does it come that you do not see the main peak of gaylussite and you see} the other peak.. gaylussite is a metastable phase and normally it transforms into calcite immediately by drying the samples.. I am surprised that you still observe it

We attribute the missing peak to preferred orientation of the carbonate crystallites in our XRD specimens; we have seen such effects previously in alkali-activated binder systems for phases which are well known to be present, and so are not particularly disturbed by the missing peak.

Additionally, the reviewer is mistaken regarding the stability and decomposition of gaylussite $\left(\mathrm{Na}_{2} \mathrm{CO}_{3} \cdot \mathrm{CaCO}_{3} \cdot 5 \mathrm{H}_{2} \mathrm{O}\right)$ - this is the stable phase in the $\mathrm{Na}_{2} \mathrm{CO}_{3}-\mathrm{CaCO}_{3}-\mathrm{H}_{2} \mathrm{O}$ system below approx. $40^{\circ} \mathrm{C}$, where pirssonite forms above this temperature [10]. Once formed, gaylussite is stable under ambient and geological conditions, and thermally decomposes only from $50^{\circ} \mathrm{C}$ and upwards in a dry atmosphere, with a peak rate of decomposition observed at $\sim 130^{\circ} \mathrm{C}$ by DTA (and $190^{\circ} \mathrm{C}$ by evolved gas analysis) [11]. It is the anhydrous $\mathrm{Na}_{2} \mathrm{Ca}\left(\mathrm{CO}_{3}\right)_{2}$ phases nyerereite and gregoryite (which are actually the thermal dehydration products of gaylussite) which are known to be unstable under atmospheric conditions, and which can decompose and partially rehydrate to form calcite and hydrous sodium carbonates [12]. However, it is necessary to subject the gaylussite to thermal treatment, not normal atmospheric conditions (average relative humidity $>60 \%$ in the exposure location used in this study), to achieve this decomposition. 
A34 - Speculation - 'The formation of nyerereite in the concretes assessed here therefore suggests that these materials are likely to undergo a high degree of selfdesiccation, which is consistent with the increased carbonation rate reported for concretes including $500 \mathrm{~kg} / \mathrm{m}^{3}$ of slag activated with $5 \mathrm{wt} . \% \mathrm{Na}_{2} \mathrm{O}$ and a w/b ratio of 0.42 (Figure 5).

We do not feel that this is unwarranted speculation; rather, we are drawing together evidence from the cements, concretes and geochemical literature to draw interesting and potentially valuable conclusions from the XRD phase identification. This is the process by which scientific understanding is advanced - if nothing is written in a paper beyond that which was already well-known by practitioners in the specific research field, the field will never be able to advance.

A35 - Can you report the Mg As well

The Mg mapping has been included

A36 - Grey level is more related to the atomic number of the element measured so CaCO3 has Ca which hasd abig number it may not appear dark...It has the same grey level as $\mathrm{CH}$ and thus brighter even than $\mathrm{C}-\mathrm{S}-\mathrm{H}$

True but irrelevant - we were not saying that the $\mathrm{CaCO}_{3}$ itself was causing the darker greyscale regions in the image, but rather that the darker regions (which are well known to be more porous - and this will be the main factor controlling greyscale intensity) are also more carbonated.

A37: Speculation: hydrotalcite has a dark greyscale level as well... a fully hydrated slag particles presented as well this dark grey level. Alkali rich gel are as well dark (see Ben Haha et al, Kocaba et al, etc...)

This section has been deleted from the paper, in response to the comments of the reviewer. However, according to the XRF analyses in Table 1, and contrary to the two 
papers cited by the reviewer, the slag used in our study has a much lower $\mathrm{MgO}$ content. According to detailed characterization of activated slag binders produced from the same source of slag as used in this study, hydrotalcite is not identified as a reaction product $[13,14]$. Considering this the EDX analyses of the darkest areas of those samples, they have a high content of carbon and cannot be assigned to fully reacted slag products according to the $\mathrm{Ca} / \mathrm{Si}$ ratios (previously Figure 14, now Figure 13), which are between 0.2 and 0.4 , instead of 0.6 to 0.9 as observed by Ben Haha in [15].

\section{A38- Gain no scientific finding is behind this statement}

Section removed.

A39 - Please try to plot $\mathrm{Mg} / \mathrm{Si} \mathrm{vs}$. Al/Si and see how does this relation is shown in a graphic? This is a better indicator especially in the presence pf hyfdrotalcite (Mg is a low mobile ion and it remains where it dissolves.. thus explains sometimes the dark rims around )

Following our answers to the queries 35,36 , and 37 from the reviewer, in our case the amount of $\mathrm{Mg}$ available in the slag is too low to promote the formation of hydrotalcite [4], as is observed in Figure $\mathrm{A}$ below, where $\mathrm{Mg} / \mathrm{Si}$ vs $\mathrm{Al} / \mathrm{Si}$ ratios of the materials in this study are compared with those obtained in silicate activated slag binders produced using BFS with a higher $\mathrm{MgO}$ content $(\sim 7 \%)$, showing that the $\mathrm{Mg} / \mathrm{Si}$ ratio here is less than 0.1 . 


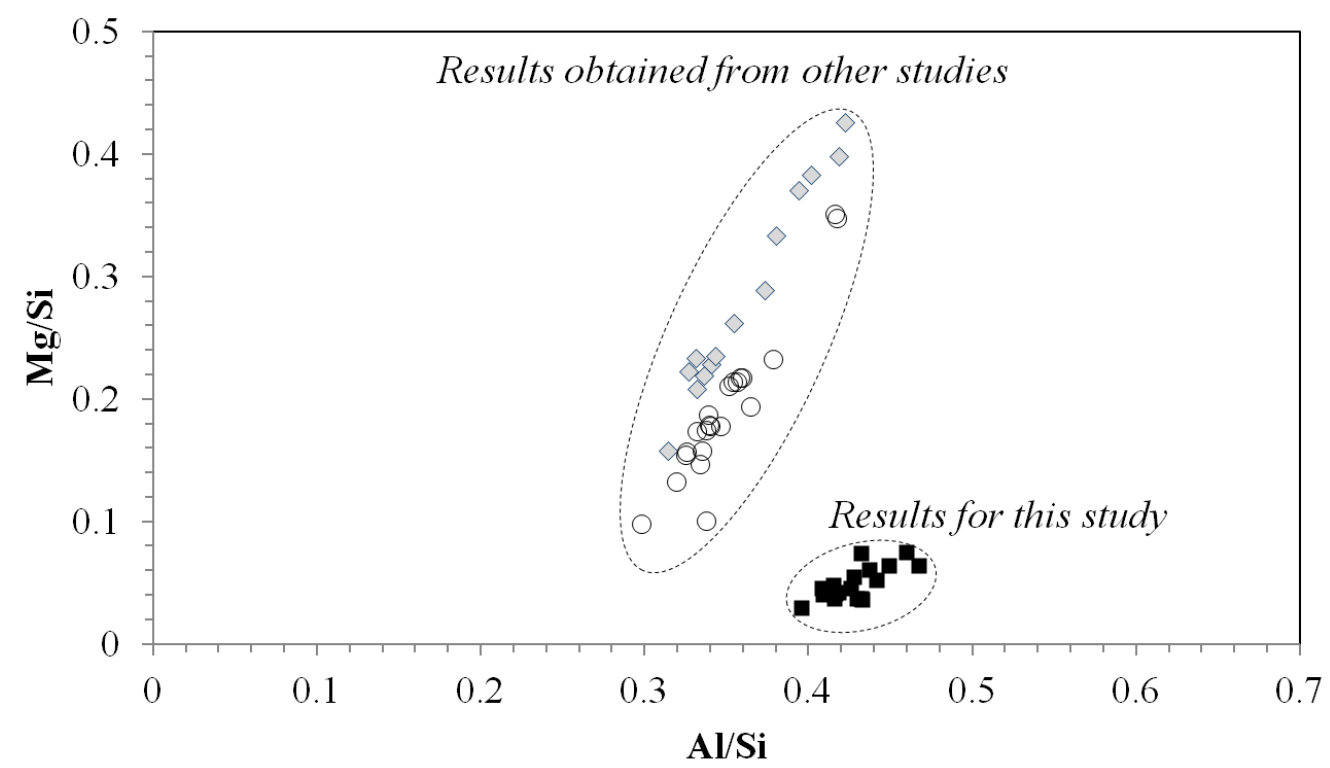

Figure A: Molar ratios $\mathrm{Mg} / \mathrm{Si}$ vs $\mathrm{Al} / \mathrm{Si}$ for uncarbonated regions of aged alkali-activated slag concretes studied here, and from other studies in our laboratory using higher-Mg slags

Reviewer \#2: This is an excellent manuscript that deals with the carbonation, under natural conditions, of alkali-activated slag concretes. This manuscript remarks an extremely important question, how accelerated durability testing results can differ from tests carried out under service life conditions.

The presented manuscript is original and well organized. The content of the paper is appropriate for the Journal. The manuscript contains a big amount of significant results, which are well presented in the form of tables and figures. The discussion and conclusions are a logical outcome data presented.

Because of the good quality of manuscript I suggest to accept it for its publication with minor revisions.

We thank to the reviewer for the positive comments.

Additionally I would suggest the following comments to the authors to be considered 
1.- Pag 6 line 16: Indicate the dimensions of the specimens on which the VPV has been determined.

This information has been included in the manuscript.

2.- Section 2.3: It is well known that alkali-activated slag concrete suffer high shrinkage (autogenous and drying) with the consequent formation of microcracks. How the presence of these microcracks is considered in the determination of VPV?

To minimise the formation of microcracks in the specimens, the cylinders (still in the molds) were covered with wet sponges after molding, and stored in a high humidity (relative humidity 95\%) immediately after demolding. To minimise formation of microcracks during the pre-conditioning of the specimens, as identified by Ismail et al. [16], the samples were dried at $100 \mathrm{C}$ for $48 \mathrm{~h}$. This information has been included in the manuscript.

3.- Page 13 line 52: " ... as it is likely that a higher concentration of alkalis in the pore solution can attract an increased concentration of $\mathrm{CO} 2$ into the concrete to promote the formation of carbonic acid ...." Please, explain in more detail this statement in the manuscript.

Please see responses to Reviewer 1 comment A28, above, where this query was discussed in detail.

4.- Figures 6, 7, 8. In the XRD patterns, there are some diffraction lines that have not been identified, specifically at 2-theta values between 60 and 70 degrees. Could the authors include the identification of these lines in the Figures?

The number of overlapping peaks in this region for the phases we identified prevents unequivocal assignment of these peaks, which are at very short d-spacings and 
correspond to very high-order reflections which are not useful in phase identification. However, all phases are identified from lower angle peaks, as per common practice in the literature.

\section{5.- Figure 14.- Indicate the number of SEM-EDX analysis done to obtain the results shown in Figure 14}

This information has been included in the manuscript

\section{References}

1. Bernal SA, Provis JL, Brice DG, Kilcullen A, Duxson P, van Deventer JSJ (2012) Accelerated carbonation testing of alkali-activated binders significantly underestimate the real service life: The role of the pore solution. Cement and Concrete Research 42(10): 1317-1326.

2. Bernal SA, Mejía de Gutierrez R, Pedraza AL, Provis JL, Rodríguez ED, Delvasto S (2011) Effect of binder content on the performance of alkaliactivated slag concretes. Cement and Concrete Research 41(1): 1-8.

3. Provis JL, Myers RJ, White CE, Rose V, van Deventer JSJ (2012) X-ray microtomography shows pore structure and tortuosity in alkali-activated binders. Cement and Concrete Research 42(6): 855-864.

4. Bernal SA, Provis JL, Mejía de Gutierrez R, Rose V (2011) Evolution of binder structure in sodium silicate-activated slag-metakaolin blends. Cement and Concrete Composites 33(1): 46-54.

5. Sanjuán MA, Andrade C, Cheyrezy M (2003) Concrete carbonation test in natural and accelerated conditions. Advances in Cement Research 15(4): 171 180.

6. Lloyd RR, Provis JL, van Deventer JSJ (2010) Pore solution composition and alkali diffusion in inorganic polymer cement. Cement and Concrete Research 40(9): 1386-1392.

7. Greenwood K, Pearce M (1953) The removal of carbon dioxide from atmospheric air by scrubbing with caustic soda in packed towers. Transactions of the Institution of Chemical Engineers 31: 201-207.

8. Myers RJ, Bernal SA, San Nicolas R, Provis JL (2013) Generalised structural description of C-(N)-A-S-H gels: The crosslinked substituted tobermorite model. Langmuir Submitted.

9. Bernal SA, Provis JL, Rose V, Mejía de Gutiérrez R (2013) High-resolution Xray diffraction and fluorescence microscopy characterization of alkali-activated slag-metakaolin binders. Journal of American Ceramic Society In press: DOI: $10.1111 /$ jace. 12247 . 
10. Smith GI, Subsurface Stratigraphy and Geochemistry of Late Quaternary Evaporites, Searles Lake, California (Geological Survey Professional Paper 1043), Washington DC, 1979.

11. Johnson DR, Robb WA (1973) Gaylussite: Thermal properties by simultaneous thermal analysis. American Mineralogist 58: 778-784.

12. Zaitsev AN, Keller J, Spratt J, Perova EN, Kearsley A (2008) Nyerereitepirssonite-calcite-shortite relationships in altered natrocarbonatites, Oldoinyo Lengai, Tanzania. Canadian Mineralogist 46(4): 843-860.

13. Bernal SA, Provis JL, Rose V, Mejía de Gutierrez R (2011) Evolution of binder structure in sodium silicate-activated slag-metakaolin blends. Cement and Concrete Composites 33(1): 46-54.

14. Bernal SA, Provis JL, Walkley B, San Nicolas R, Gehman J, Brice DG, Kilcullen A, Duxson P, van Deventer JSJ (2013) Gel nanostructure in alkaliactivated binders based on slag and fly ash, and effects of accelerated carbonation. Cement and Concrete Research: Submitted.

15. Ben Haha M, Lothenbach B, Le Saout G, Winnefeld F (2012) Influence of slag chemistry on the hydration of alkali-activated blast-furnace slag - Part II: Effect of $\mathrm{Al}_{2} \mathrm{O}_{3}$. Cement and Concrete Research 42(1): 74-83.

16. Ismail I, Bernal SA, Provis JL, Hamdan S, van Deventer JSJ (2013) Dryinginduced changes in the structure of alkali-activated pastes. Journal of Materials Science 48: 3566-3577. 


\section{University Library}

\section{- M M N E R VA A gateway to Melbourne's research publications}

Minerva Access is the Institutional Repository of The University of Melbourne

Author/s:

Bernal, SA;San Nicolas, R;Provis, JL;Mejia de Gutierrez, R;van Deventer, JSJ

Title:

Natural carbonation of aged alkali-activated slag concretes

Date:

2014-04-01

Citation:

Bernal, S. A., San Nicolas, R., Provis, J. L., Mejia de Gutierrez, R. \& van Deventer, J. S. J. (2014). Natural carbonation of aged alkali-activated slag concretes. MATERIALS AND STRUCTURES, 47 (4), pp.693-707. https://doi.org/10.1617/s11527-013-0089-2.

Persistent Link:

http://hdl.handle.net/11343/282877 